\title{
Modifying glycyrrhetinic acid liposomes with liver-targeting ligand of galactosylated derivative: preparation and evaluations
}

\author{
Jing Chen ${ }^{1, *}$, Yuchao Chen ${ }^{1, *}$, Yi Cheng ${ }^{1}$, Youheng Gao ${ }^{1}$, Pinjing Zheng ${ }^{1}$, Chuangnan \\ $\mathrm{Li}^{2}$, Yidan Tong ${ }^{1}$, Zhao $\mathrm{Li}^{1}$, Wenhui $\mathrm{Luo}^{3}$ and Zhao Chen ${ }^{3}$ \\ ${ }^{1}$ School of Chinese Materia Medica, Guangzhou University of Chinese Medicine, Guangdong, China \\ ${ }^{2}$ The Second School of Clinic Medicine, Guangzhou University of Chinese Medicine, Guangdong, China \\ ${ }^{3}$ Guangdong Second Traditional Chinese Medicine Hospital (Guangdong Research Institute of Traditional Chinese Medicine \\ Engineering Technology), Guangdong, China \\ *These authors have equally contributed to this work \\ Correspondence to: Yi Cheng, email: chengyi@gzucm.edu.cn \\ Youheng Gao, email: gaoyouheng@gzucm.edu.cn
}

Keywords: liver-targeting; galactosylated derivative; glycyrrhetinic acid liposomes; liver disease therapeutic Received: May 18, $2017 \quad$ Accepted: August 26, $2017 \quad$ Published: October 27, 2017

Copyright: Chen et al. This is an open-access article distributed under the terms of the Creative Commons Attribution License 3.0 (CC BY 3.0), which permits unrestricted use, distribution, and reproduction in any medium, provided the original author and source are credited.

\section{ABSTRACT}

In this study, novel glycyrrhetinic acid (GA) liposomes modified with a livertargeting galactosylated derivative ligand ( $\mathrm{Gal}$ ) were prepared using a film-dispersion method. To characterize the samples, particle size, zeta potential, drug loading, and encapsulation efficiency were performed. Moreover, plasma and tissues were pre-treated by liquid-liquid extraction and analyzed by high-performance liquid chromatography-tandem mass spectrometry (LC-MS/MS). The results showed that the mean residence times (MRTs) and the area under the curve (AUC) of GA liposomes with Gal (Gal-GA-LP), and GA liposomes (GA-LP) were higher than the GA solution (GA$S$ ) in plasma. The tissue (liver) distribution of Gal-GA-LP was significantly different in contrast to GA-LP. The relative intake rate (Re) of Gal-GA-LP and GA-LP in the liver was 4.752 and 2.196, respectively. The peak concentration ratio (Ce) of Gal-GA-LP and GA-LP in the liver was 2.796 and 1.083, respectively. The targeting efficiency (Te) of Gal-GA-LP and GA-LP in the liver was $48.193 \%$ and $34.718 \%$, respectively. Taken together, the results indicate that Gal-GA-LP is an ideal complex for liver-targeting, and has great potential application in the clinical treatment of hepatic diseases. Drug loading and releasing experiments also indicated that most liposomes are spherical structures and have good dispersity under physiologic conditions, which could prolong GA release efficiency in vitro.

\section{INTRODUCTION}

Glycyrrhetinic acid (GA), serving as an active principal ingredient of glycyrrhizin, is hydrolyzed by glucuronidase after oral administration [1]. GA has been identified as a potential anti-hepatotoxic agent [2, $3]$ and has been widely used in the clinical treatment of hepatic diseases $[4,5]$. As an attractive inhibitor, GA has multi-beneficial pharmacologic activities, including anti-ulcerative [6], anti-inflammatory [7], anti-viral [8], and interferon induction [9]; however, GA is lipophilic and thus has low solubility in water $(<0.01 \mathrm{mg} / \mathrm{mL})$ and may cause unwanted sodium retention or potassium loss [10]. GA tablets are administered orally for most patients; injections are rarely reported. To avoid side effects and maintain the essential concentration of GA, drug delivery based on nanoparticles was developed. Nanoparticle and nanotechnologic materials, including 
liposomes, polymeric micelles, and dendrimers, have been shown to simultaneously have higher efficacy and lower cytotoxicity [11].

Liposomes are ideal formulations which have been approved by the Food and Drug Administration (FDA) [12]. A liposomal injection system is a highly credible method that increases the local concentration of a drug in the vicinity of tumors by altering the bio-distribution of associated drugs [13, 14]. Moreover, liposomes can reduce the amount of drug that penetrates healthy tissues, which is a major cause of cytotoxicity [15]. A targeting liposomal injection system is under development in our laboratory as a suitable strategy to increase the concentration of drugs in some specific tissue sites. The asialoglycoprotein receptor is abundant in hepatocytes, minimally expressed in extra-hepatic tissues, and provides attractive advantages for hepatocyte-mediated delivery [16]. Some reports have focused on glycosylated nanocarriers for targeted delivery to specific cell types have also been shown to be highly efficient $[17,18]$. While hepatocytes display a number of targets, drug-ligand conjugates exhibit large variations based on different sites and ligands, thus galactosylated derivative ligands offer attractive options for asialoglycoprotein receptors $[19,20]$. In our previous study we used a novel galactosylated derivative ligand (Gal) to enhance drug liver-targeting delivery. The novel Gal specifically recognizes the asialoglycoprotein receptor [21].

Herein, we determined whether or not the GA liposomes with Gal (Gal-GA-LP) have liver-targeting efficiency. First, we prepared GA liposomes (GA-LP) and Gal-GA-LP to improve GA anti-hepatic carcinoma and liver-targeting properties and characterized GALP and Gal-GA-LP by high-performance liquid chromatography-tandem mass spectrometry (LC-MS). Then, GA-LP and Gal-GA-LP were evaluated by release efficiency in vitro, hemolysis testing, and cellular uptake experiments. We also investigated the pharmacokinetics and targeting profile of Gal-GA-LP compared with GALP and GA solution (GA-S) by intravenous injection. The pharmacokinetic parameters included terminal elimination half-life $\left(\mathrm{T}_{1 / 2 \mathrm{z}}\right)$, apparent tissue clearance $(\mathrm{CL})$, apparent volume of distribution $\left(\mathrm{V}_{\mathrm{d}}\right)$, AUC, MRT, bio-distribution data, relative intake rate (Re), targeting efficiency (Te), and peak concentration ratio (Ce). Of note, the drug content of GA in plasma and tissues is in nanogram amounts only. Therefore, as a result, the high-performance liquid chromatography (HPLC) method is not suitable for pharmacokinetic and bio-distribution studies involving GA.

Compared with other detection techniques, the LCMS/MS method is more sensitive, selective, and accurate. Some reports have studied GA in plasma by LC-MS/MS $[22,23]$, but simultaneous detection of GA in plasma and tissues has rarely been reported, and use of the LC-MS/ MS method in detecting GA with GA liposomes and GA-S has never been reported. It was also has been reported that PEG-modified liposome loading GA, and a thorough review on GA receptor-targeting and GA-delivering carriers $[24,25]$. However, this study was novel in that it provides a new kind of liposome modification that results in better cellular uptake of GA, as well as a LC/MS-based analysis of the liposomes.

It was the first time for our experimental team to use the synthesis of Gal compounds and modified glycyrrhetinic acid liposomes. Study the properties and target of liposomes in vitro and in vivo. In vitro and in vivo evaluations are crucial steps before the clinical use of Gal-GA-LP. At the same time, LC-MS / MS method was used to detect the changes of GA in blood and tissue (heart, liver, spleen, lung and kidney). We anticipate that Gal-GA-LP will enhance liver-targeting efficiency and facilitate clinical treatment of liver disease.

\section{RESULTS}

\section{GA-LP and Gal-GA-LP preparations}

Encapsulation efficiency (EE), particle diameter, and polydispersity were measured as described above, and the results are shown in Table 1. When determining one factor, the other factors were regarded as fixed parameters. The first factor was the proportion of GA-to-blank liposomes. The results indicated that a suitable proportion of GA could improve the encapsulation efficiency, as well as dispersity; however, the particle size decreased gradually when improving the GA proportion because that GA could be mixed uniformly with blank liposomes only when relatively saturated. Thus, we determined the optimal proportion of 1:9 (GA/blank liposomes). The molar ratio of Gal: EPC, when serving as the second factor, was examined. We selected 5\% as the molar ratio of Gal: EPC in subsequent tests. The type and amount of lyophilized protective agent were detected to form stable lyophilized GA liposomes without collapse. The preparations of the thin film dispersion and ethanol injection methods were compared, which showed that the former increased encapsulation efficiency and the latter decreased particle size and polydispersity index.

In brief, the optimal conditions for the production of GA-LP and Gal-GA-LP were as follows: the proportion of GA and blank liposomes was 1:9; the molar ratio of Gal: EPC was $5 \%$; the type of lyophilized protective agent was glucose-mannitol; the proportion of lyophilized protective agent: EPC was 6:1; and the thin film dispersion method was the method of preparation.

\section{Characterizations of GA-LP and Gal-GA-LP}

Spherical particles of GA-LP and Gal-GA-LP were observed in transmission electron microscope (TEM) images (Figure 1A, 1B). GA-LP and Gal-GA-LP were 
Table 1: Encapulation efficiency, mean particle diameter, and polydispersity index when one variable parameter was fixed

\begin{tabular}{|c|c|c|c|c|c|}
\hline $\begin{array}{l}\text { Order of } \\
\text { evaluation }\end{array}$ & Variable & Level & $\begin{array}{c}\text { Encapulation } \\
\text { efficiency } \\
(\%) \pm \text { S.D. }\end{array}$ & $\begin{array}{c}\text { Mean particle } \\
\text { diameter }(\mathrm{nm}) \\
\quad \pm \text { S.D. }\end{array}$ & Polydispersityindex \pm S.D. \\
\hline \multirow[t]{4}{*}{$1 \mathrm{st}$} & $\begin{array}{l}\text { The proportion } \\
\text { of GA to blank } \\
\text { liposomes (w/w) }\end{array}$ & $1: 6$ & $81.45 \pm 0.60$ & $225.43 \pm 0.65$ & $0.5033 \pm 0.0071$ \\
\hline & & $1: 8$ & $83.24 \pm 0.92$ & $209.13 \pm 2.44$ & $0.4230 \pm 0.0030$ \\
\hline & & $1: 9$ & $91.06 \pm 0.59$ & $221.17 \pm 2.76$ & $0.4223 \pm 0.0055$ \\
\hline & & $1: 10$ & $78.64 \pm 1.07$ & $227.47 \pm 2.33$ & $0.4830 \pm 0.0020$ \\
\hline \multirow[t]{4}{*}{ 2nd } & $\begin{array}{l}\text { The molar ratio } \\
\text { of Gal to EPC }\end{array}$ & $3 \%$ & $91.28 \pm 0.67$ & $190.60 \pm 0.75$ & $0.3850 \pm 0.0046$ \\
\hline & & $5 \%$ & $85.52 \pm 0.62$ & $187.17 \pm 0.85$ & $0.3217 \pm 0.0068$ \\
\hline & & $7 \%$ & $84.55 \pm 0.10$ & $196.17 \pm 0.86$ & $0.4023 \pm 0.0068$ \\
\hline & & $9 \%$ & $80.92 \pm 0.57$ & $199.73 \pm 0.38$ & $0.4410 \pm 0.0030$ \\
\hline \multirow[t]{10}{*}{$3 \mathrm{rd}$} & $\begin{array}{l}\text { The type of } \\
\text { cryoprotectant }\end{array}$ & mannitol & $78.32 \pm 0.48$ & $221.50 \pm 0.98$ & $0.5383 \pm 0.0067$ \\
\hline & & trehalose & $77.88 \pm 0.31$ & $218.27 \pm 0.97$ & $0.4530 \pm 0.0030$ \\
\hline & & sucrose & $91.28 \pm 0.03$ & $232.70 \pm 0.66$ & $0.4793 \pm 0.0025$ \\
\hline & & glucose & $86.94 \pm 0.20$ & $189.33 \pm 0.75$ & $0.5080 \pm 0.0026$ \\
\hline & & $\begin{array}{l}\text { glucose- } \\
\text { mannitol }\end{array}$ & $93.22 \pm 0.62$ & $185.83 \pm 0.47$ & $0.3457 \pm 0.0025$ \\
\hline & & $\begin{array}{l}\text { glucose- } \\
\text { trehalose }\end{array}$ & $87.25 \pm 0.75$ & $212.37 \pm 0.96$ & $0.4150 \pm 0.0025$ \\
\hline & & $\begin{array}{l}\text { sucrose- } \\
\text { trehalose }\end{array}$ & $87.71 \pm 0.73$ & $212.20 \pm 0.80$ & $0.4280 \pm 0.0044$ \\
\hline & & sucrose-glucose & $84.55 \pm 0.64$ & $234.63 \pm 0.61$ & $0.5347 \pm 0.0020$ \\
\hline & & $\begin{array}{l}\text { mannitol- } \\
\text { trehalose }\end{array}$ & $88.65 \pm 0.39$ & $225.20 \pm 0.75$ & $0.4660 \pm 0.0034$ \\
\hline & & $\begin{array}{l}\text { mannitol- } \\
\text { sucrose }\end{array}$ & $91.47 \pm 0.57$ & $193.43 \pm 0.87$ & $0.3853 \pm 0.0025$ \\
\hline \multirow[t]{5}{*}{4 th } & $\begin{array}{l}\text { The } \\
\text { proportion of } \\
\text { cryoprotectant } \\
\text { to EPC }(w / w)\end{array}$ & $4: 1$ & $82.57 \pm 0.66$ & $225.30 \pm 1.28$ & $0.4677 \pm 0.0051$ \\
\hline & & $6: 1$ & $84.79 \pm 0.63$ & $210.00 \pm 0.78$ & $0.3413 \pm 0.0045$ \\
\hline & & $8: 1$ & $81.83 \pm 0.84$ & $218.27 \pm 0.65$ & $0.4617 \pm 0.0045$ \\
\hline & & $10: 1$ & $81.48 \pm 0.75$ & $211.07 \pm 0.78$ & $0.3997 \pm 0.0035$ \\
\hline & & $12: 1$ & $81.03 \pm 0.99$ & $230.37 \pm 0.82$ & $0.4593 \pm 0.0056$ \\
\hline \multirow[t]{2}{*}{5 th } & $\begin{array}{l}\text { The method of } \\
\text { preparation }\end{array}$ & $\begin{array}{l}\text { thin-film } \\
\text { dispersion } \\
\text { method }\end{array}$ & $92.77 \pm 0.62$ & $181.00 \pm 0.66$ & $0.3740 \pm 0.0045$ \\
\hline & & $\begin{array}{c}\text { ethanol injection } \\
\text { method }\end{array}$ & $81.71 \pm 0.95$ & $188.50 \pm 0.75$ & $0.4983 \pm 0.0040$ \\
\hline
\end{tabular}

Notes: Data shown represent the mean \pm S.D. Abbreviations: S.D., standard deviation. 
prepared using the thin film dispersion method under optimal conditions, and the results are shown in Table 2. The average sizes of Gal-GA-LP and GA-LP are shown in Figure $1 \mathrm{C}$ and $1 \mathrm{D}$ and the zeta potentials are shown in Figure 1E and 1F. The particle size of Gal-GA-LP was smaller than GA-LP. The Zetasizer Nano ZS90 Analyser showed that Gal-GA-LP had a similar size, suitable potential zeta, and uniform dispersion. In addition, the EE (\%) and drug loading (DL) indicated the quality and clinical effects of the liposomes. The EE (\%) values were $>80 \%(92.89 \pm 0.91 \%)$ and the DL (\%) values were good $(8.97 \pm 0.09 \%)$. No significant changes were observed when adding Gal to the liposome.

\section{Studies of in vitro drug release}

The in vitro drug release behaviors of GA-S, GALP, and Gal-GA-LP have been used for comparison. The

A

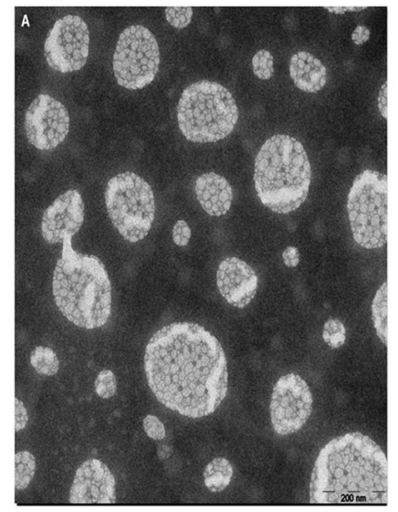

C

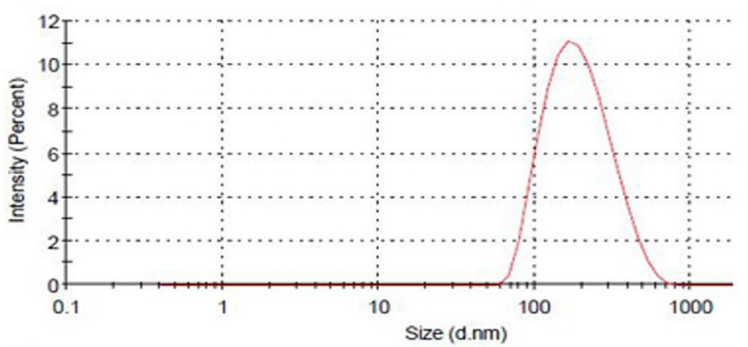

E

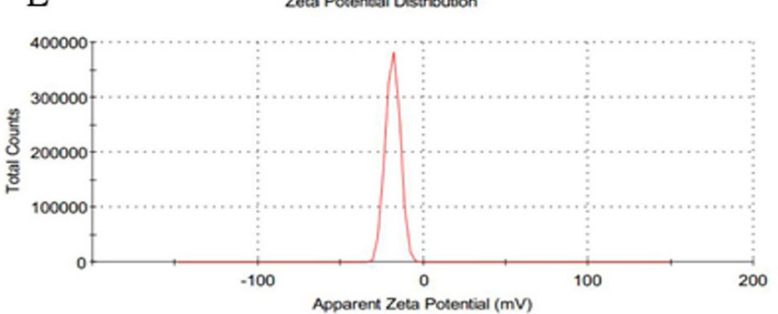

cumulative release behaviors of GA-S, GA-LP, and GalGA-LP are shown in Figure 2. Within $24 \mathrm{~h}$ at $37^{\circ} \mathrm{C} \pm 0.5^{\circ} \mathrm{C}$, $>90 \%$ of GA-S was released. In comparison, the GA-LP released $60 \%$ of drug, while Gal-GA-LP released $54 \%$. Then, $40 \%-46 \%$ of the entrapped GA was further released during the subsequent $24 \mathrm{~h}$ of incubation. Taking into account that the release of GA from GA-S was rapid and almost complete within $12 \mathrm{~h}$, the retention time of GA during release was dramatically prolonged by liposomal encapsulation. Moreover, no significant changes were found in terms of release characteristics when adding Gal to the liposomes.

\section{Stability}

The stability data of GA-LP and Gal-GA-LP are summarized in Table 3. The leakage rate (LR) of GALP and Gal-GA-LP ranged from $1.53-6.08 \%$ and 1.41 -

B
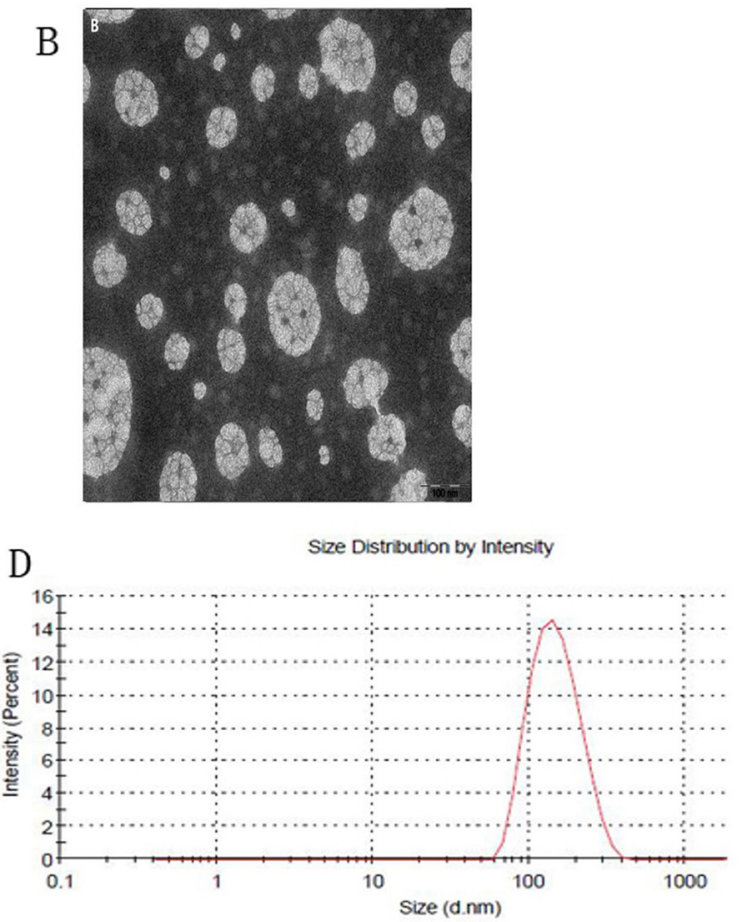

F

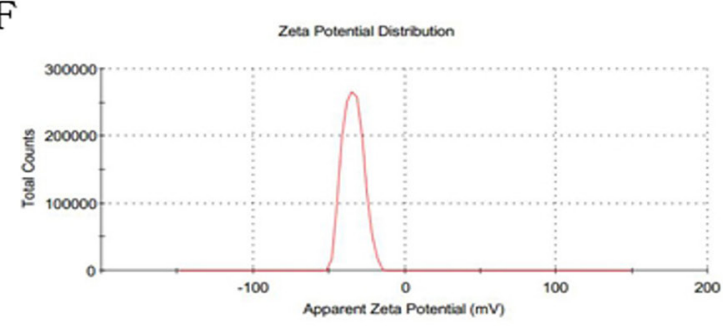

Figure 1: Transmission electron microscope photographs, size distributions and zeta potentials of GA-LP and GalGA-LP. Note: Magnification $\times 50,000$, (A) transmission electron microscope photographs of GA-LP, (B) transmission electron microscope photographs of Gal-GA-LP, (C) size distribution of GA-LP, (D) size distribution of Gal-GA-LP, (E) zeta potential of GA-LP, (F) zeta potential of Gal-GA-LP.

Abbreviations: GA-LP, glycyrrhetinic acid liposomes; Gal-GA-LP, glycyrrhetinic acid liposomes modified with liver-targeting ligand of galactosylated derivative. 
Table 2: The characterizations of the liposomes $(n=3)$

\begin{tabular}{|c|c|c|c|c|c|}
\hline Sample & $\begin{array}{l}\text { Particle size } \\
(\mathbf{n m}) \pm \text { S.D. }\end{array}$ & $\begin{array}{c}\text { Zeta potential (mV) } \\
\pm \text { S.D. }\end{array}$ & $\begin{array}{c}\text { Polydispersity } \\
\text { index } \pm \text { S.D. }\end{array}$ & $\begin{array}{c}\text { Encapulation } \\
\text { efficiency }(\%) \pm \text { S.D. }\end{array}$ & $\begin{array}{c}\text { Drug loading } \\
(\%) \pm \text { S.D. }\end{array}$ \\
\hline GA-LP & $192.10 \pm 2.30$ & $-22.30 \pm 1.20$ & $0.3923 \pm 0.0057$ & $83.47 \pm 1.29$ & $8.39 \pm 0.13$ \\
\hline Gal-GA-LP & $150.67 \pm 1.60$ & $-35.50 \pm 0.96$ & $0.2890 \pm 0.0062$ & $92.89 \pm 0.91$ & $8.97 \pm 0.09$ \\
\hline
\end{tabular}

Notes: Data shown represent the mean \pm S.D.

Abbreviations: S.D., standard deviation; GA-LP, glycyrrhetinic acid liposomes; Gal-GA-LP, glycyrrhetinic acid liposomes modified with liver-targeting ligand of galactosylated derivative.

$5.45 \%$, respectively. No aggregation or precipitation of nanoparticles was observed during storage for 3 months. The results showed that the properties of lyophilized GA-LP and Gal-GA-LP were stable to ensure $>94 \%$ GA content in the liposomes. The stability study indicated that a suitable formulation (lyophilized liposomes) decreased the LR.

\section{Hemolysis testing}

Hemolysis data are shown in Figure 3. In two groups of GA liposomes, including GA-LP and Gal-GA$\mathrm{LP}$, hemolysis only occurred in the positive control tube for $6 \mathrm{~h}$; however, the 4th and 5th GA-S tubes had the same phenomenon as the positive control tube with respect to hemolysis. After being re-mixed, red blood cells were uniformly distributed in tubes $1^{\text {st }}-6^{\text {th }}$ of GA-LP and GalGA-LP without erythrocyte agglutination, while the 4th and $5^{\text {th }}$ GA-S tubes exhibited erythrocyte agglutination. The drug concentration of GA-LP and Gal-GA-LP was highest in the $5^{\text {th }}$ tube, in which there was no hemolysis and agglutination at $37^{\circ} \mathrm{C}$. Therefore, the GA liposome is a safe formulation for injection. In addition, Gal is a safe drug carrier for targeted drug delivery.

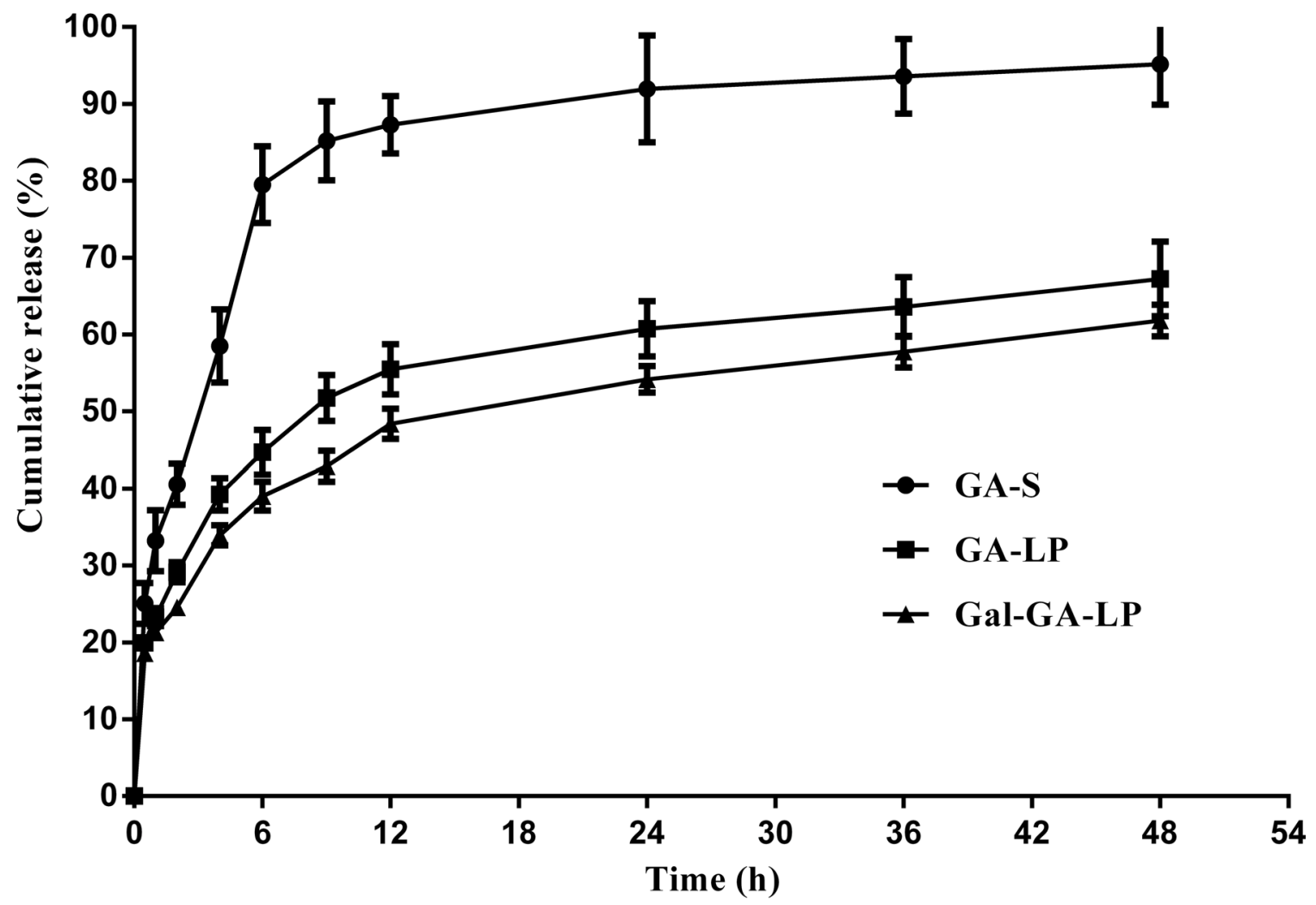

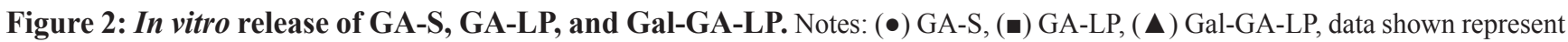
the mean \pm S.D.

Abbreviations: GA-S, glycyrrhetinic acid solvent; GA-LP, glycyrrhetinic acid liposomes; Gal-GA-LP, glycyrrhetinic acid liposomes modified with liver-targeting ligand of galactosylated derivative. 
Table 3: The stability of GA liposomes (GA-LP and Gal-GA-LP)

\begin{tabular}{lccc}
\hline \multirow{2}{*}{ Condition } & & \multicolumn{2}{c}{ Leakage rate (\%) \pm S.D. } \\
\cline { 3 - 4 } & & GA-LP & Gal-GA-LP \\
\hline $25^{\circ} \mathrm{C} \pm 2{ }^{\circ} \mathrm{C}, 60 \% \pm 5 \% 2$ weeks & $1^{\text {st }}$ month & $2.39 \pm 0.49$ & $2.00 \pm 0.20$ \\
$25^{\circ} \mathrm{C} \pm 2{ }^{\circ} \mathrm{C}$ & $2^{\text {nd }}$ month & $1.53 \pm 0.54$ & $1.41 \pm 0.55$ \\
& $3^{\text {rd }}$ month & $3.96 \pm 0.49$ & $3.20 \pm 0.53$ \\
& $3^{\text {rd }}$ month & $6.08 \pm 0.62$ & $5.45 \pm 0.41$ \\
$4{ }^{\circ} \mathrm{C} \pm 1{ }^{\circ} \mathrm{C}$ & $6^{\text {th }}$ month & $3.28 \pm 0.27$ & $2.75 \pm 0.73$ \\
\hline
\end{tabular}

Notes: Data shown represent the mean \pm S.D.

Abbreviations: S.D., standard deviation; GA, glycyrrhetinic acid; GA-LP, glycyrrhetinic acid liposomes; Gal-GA-LP, glycyrrhetinic acid liposomes modified with liver-targeting ligand of galactosylated derivative.

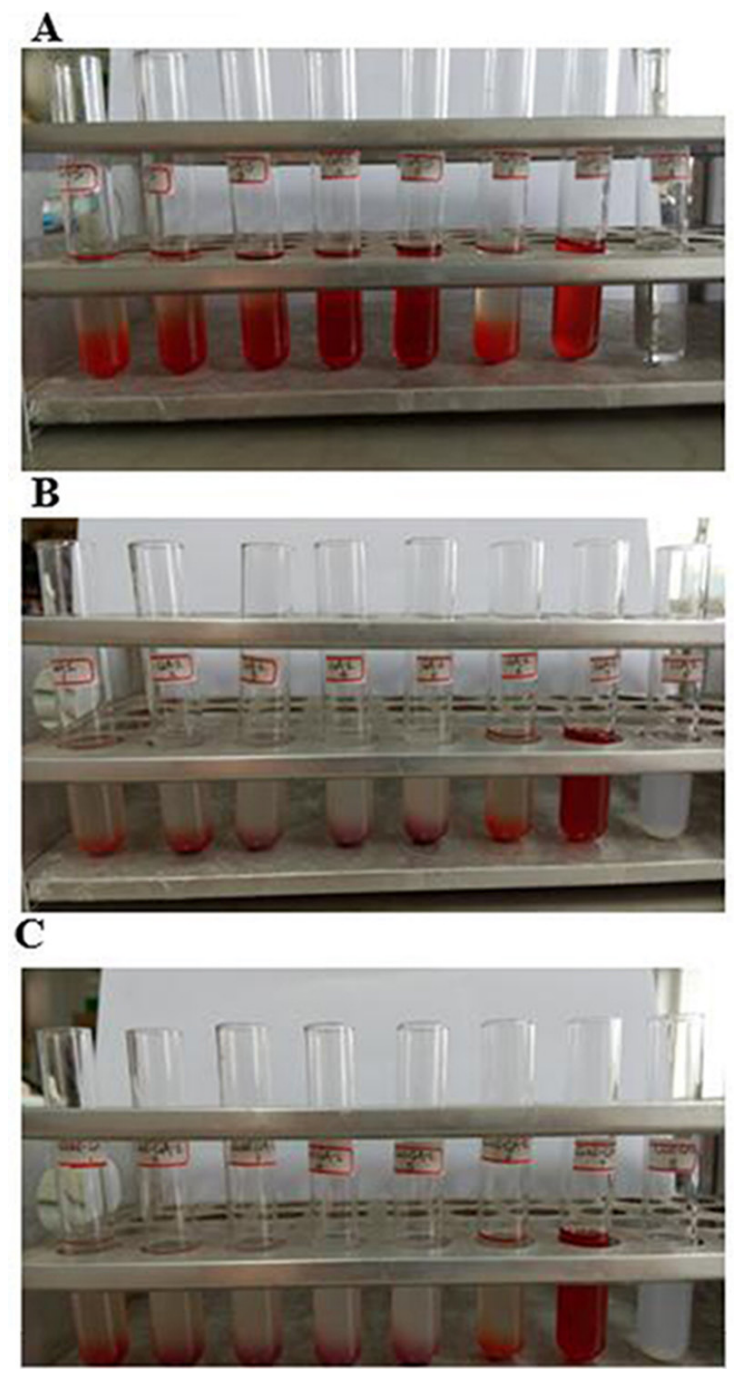

Figure 3: Hemolysis testing of GA-S, GA-LP, and Gal-GA-LP. Notes: (A) GA-S, (B) GA-LP, (C) Gal-GA-LP.

Abbreviations: GA-S, glycyrrhetinic acid solvent; GA-LP, glycyrrhetinic acid liposomes; Gal-GA-LP, glycyrrhetinic acid liposomes modified with liver-targeting ligand of galactosylated derivative. 


\section{In vitro cellular uptake}

We determined the intracellular GA concentration using HPLC to determine whether or not the uptake of GA liposomes could be promoted in HepG2 cells. The results are shown in Figure 4. The amount of intracellular GA in GA-LP $\left(60.24 \pm 9.07 \mathrm{ng} / 10^{5}\right.$ cell $)$ and Gal-GA-LP $\left(86.28 \pm 12.13 \mathrm{ng} / 10^{5}\right.$ cell $)$ was greater than GA-S (53.59 $\pm 8.44 \mathrm{ng} / 10^{5}$ cell), suggesting that GA in liposomes increased HepG2 cellular uptake, and Gal-GA-LP had a higher drug concentration than GALP because of Gal ligand. Therefore, we performed a competitive binding experiment with the addition of Gal beforehand, followed by GA-S, GA-LP, and GalGA-LP. As a result, the GA concentrations in HepG2 cells decreased significantly, indicating that Gal targeted the receptor in advance, and then hindered binding of Gal from Gal-GA-LP to the receptor. Thus, the GA concentration of Gal-GA-LP (1.57-fold) was greater than Gal+Gal-GA-LP.

\section{Optimization of LC-MS/MS conditions}

\section{Chromatographic conditions}

Ursolic acid was selected as the IS because its chromatographic behavior was similar to GA. To select the mobile-phase modifier, ammonium acetate was compared with acetic acid. Ammonium acetate not only enhanced deprotonation in the ESI-negative mode, but also obtained a good peak shape. An acetonitrile: $5 \mathrm{mmoL}$ ammonium acetate $(70: 30[\mathrm{v} / \mathrm{v}])$ water solution achieved excellent peak shape and obtained a maximum peak response. Satisfactory separation and a suitable retention time were achieved with a flow rate of $0.3 \mathrm{~mL} / \mathrm{min}$.

\section{Mass spectrometry}

The signal transitions of GA and IS were observed after being broken into pieces in the collision cell. The signal from the $\mathrm{m} / \mathrm{z} \quad 469.26 \rightarrow 387.11$ transition was

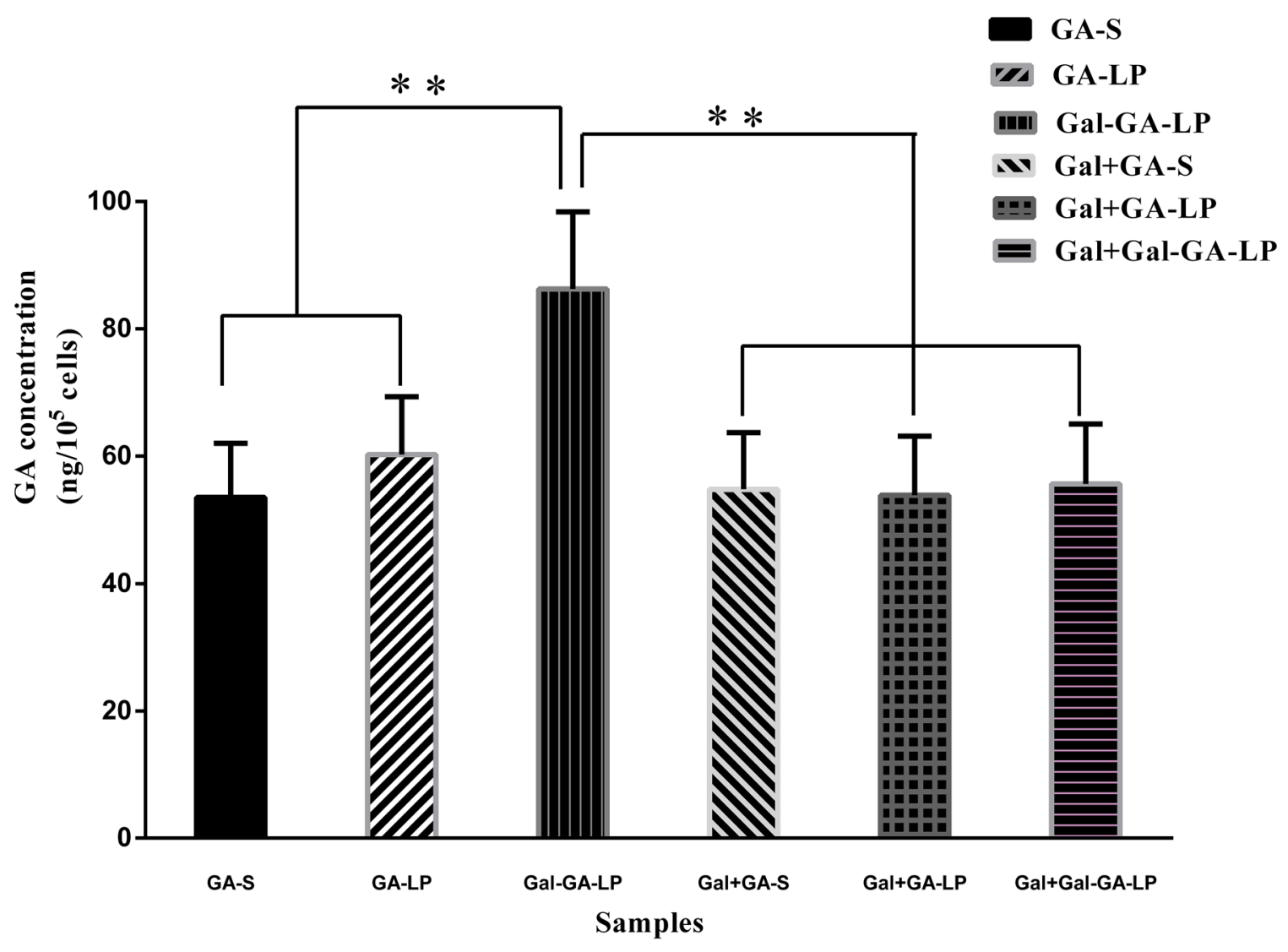

Figure 4: GA concentrations of GA-S, GA-LP, Gal-GA-LP, Gal+GA-S, Gal+GA-LP, and Gal+Gal-GA-LP in HepG2 cells. Note: Data shown represent the mean \pm S.D.,${ }^{* *} P<0.05$.

Abbreviations: GA-S, glycyrrhetinic acid solvent; GA-LP, glycyrrhetinic acid liposomes; Gal-GA-LP, glycyrrhetinic acid liposomes modified with liver-targeting ligand of galactosylated derivative; Gal+GA-S, galactosylated derivative was added for $4 \mathrm{~h}$ previously, then glycyrrhetinic acid solvent was added for further $6 \mathrm{~h}$; Gal+GA-LP, galactosylated derivative was added for $4 \mathrm{~h}$ previously, then glycyrrhetinic acid liposomes were added for further $6 \mathrm{~h}$; Gal+Gal-GA-LP, galactosylated derivative was added for $4 \mathrm{~h}$ previously, then glycyrrhetinic acid liposomes mediated with galactosylated derivative were added for further $6 \mathrm{~h}$. 
measured to be the most abundant and stable transition. Therefore, the transition of $\mathrm{m} / \mathrm{z} \quad 469.26 \rightarrow 387.11$ was selected for quantification of GA (Figure 5A). Similarly, the ion transition of $\mathrm{m} / \mathrm{z} 455.24 \rightarrow 409.09$ was selected for IS (Figure 5B).

\section{Method validation}

\section{Specificity and selectivity}

The newly developed simple method, LC-MS/ MS, was more specific and less time consuming when compared with the previously reported methods [26, 27]. The typical LC-MS/MS chromatograms of blank plasma spiked with GA or IS, a random plasma or tissue homogenate sample after administration of GA, and a random sample spiked with IS are shown in Figure 6. The retention times of GA and IS were 1.61 and 3.37 min, respectively. Other LC-MS/MS chromatograms of bio-samples, including heart, liver, spleen, lung, and kidney, were similar to plasma (not shown in Figure 6). Thus, there was no significant endogenous interference in plasma and tissue homogenates of heart, liver, spleen, lung, and kidney, indicating that the method was selective.

\section{Linearity and limit of quantification}

The linearity of the LC-MS/MS method was evaluated using a calibration curve within the range of 4-6000 $\mathrm{ng} / \mathrm{mL}$. The representative equations for the standard curves are listed in Table 4. In Table 4, $\mathrm{Y}$ represents the ratio of the GA peak area:IS and $\mathrm{X}$ represents the GA concentration. The LOQ denotes the lowest amount of analyte that could be precisely and accurately quantified. In the current study, the LOQ of plasma and various tissues was $3 \mathrm{ng} / \mathrm{mL}$.

\section{Precision and accuracy}

The results of precision and accuracy are summarized in Table 5. As demonstrated, the intra- and inter-day precision (RSD) ranged from $2.63 \%-9.83 \%$ and $2.02 \%$ $8.19 \%$, respectively. The accuracy (RE) of GA ranged from $-3.71 \%$ to $9.60 \%$. Both values were $<10 \%$. Therefore, this analysis method had high accuracy and precision.
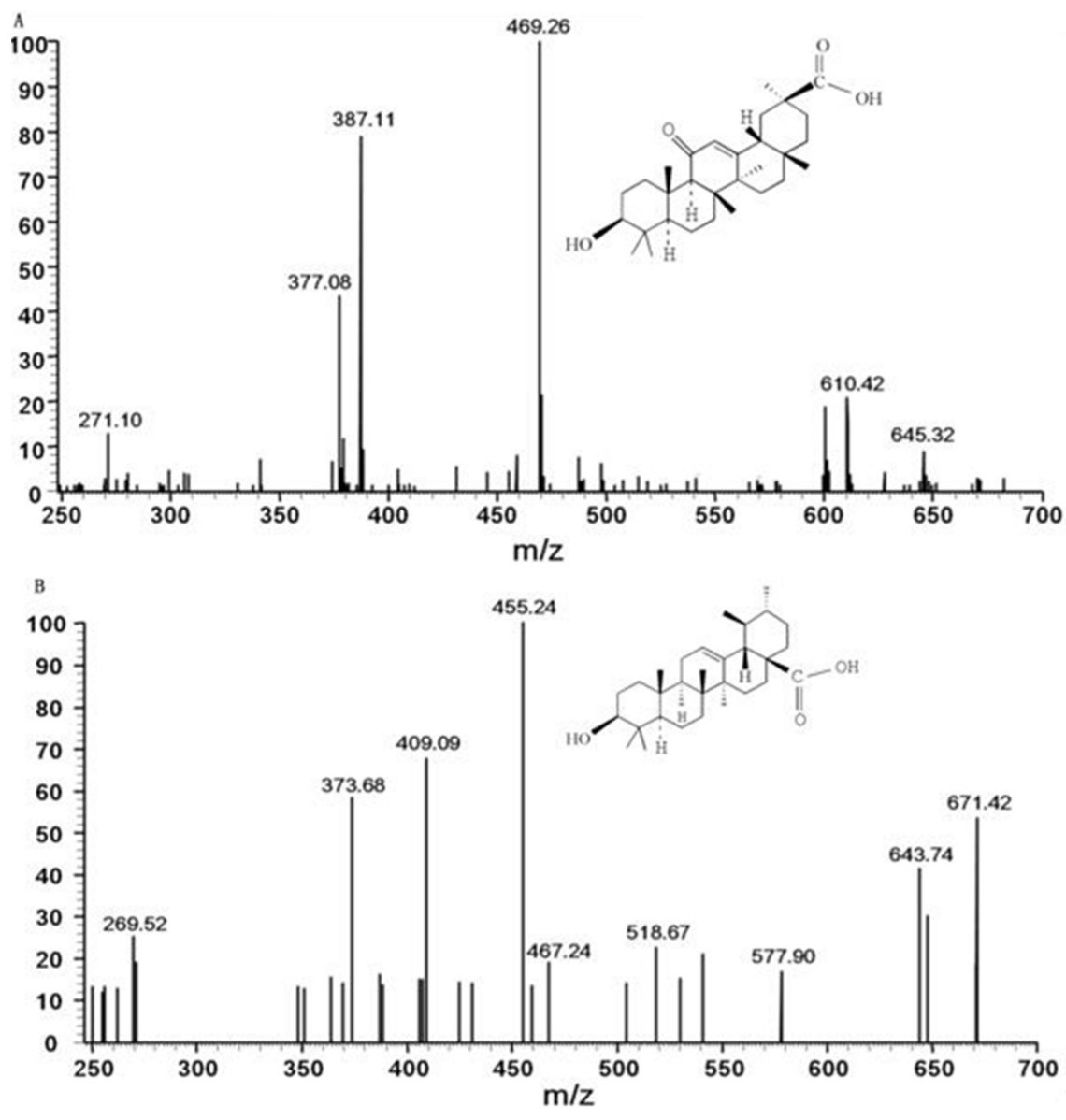

Figure 5: Scan spectra of production for GA and IS. Notes: (A) GA. (B) IS

Abbreviations: GA, glycyrrhetinic acid; IS, ursolic acid. 


\section{Recovery and matrix effect}

Extraction recoveries and the matrix effect of GA are summarized in Table 6 . The extraction recoveries of GA in plasma and tissues were in the ranges of $78.75 \%$ $84.75 \%$ and $79.37 \%-88.70 \%$, respectively. In addition, the matrix effect of GA ranged from $87.98 \%-92.68 \%$, 90.49\%-92.96\%, and $90.77 \%-94.01 \%$ at concentrations of 25, 800, and $2000 \mathrm{ng} / \mathrm{mL}$, respectively. According to the requirements of the Pharmacopoeia of China People's Republic (2010 edition, part II), these extraction recoveries were within the acceptable range. The matrix effect indicated that the matrix had no significant matrix ionization suppression or enhancement.

\section{Stability}

The stability of GA in plasma and tissues (heart, liver, spleen, lung, and kidney) was determined at three concentrations $(25,800$, and $2000 \mathrm{ng} / \mathrm{mL})$. The results are shown in Table 7. Under the three conditions described above, the RSD was $<15 \%$. The results indicated that GA was stable under the experimental conditions.

\section{Pharmacokinetic and bio-distribution study}

The mean plasma concentration-time curves of GA-S, GA-LP, and Gal-GA-LP after a single intravenous injection are shown in Figure 7A. Compared with GA-S
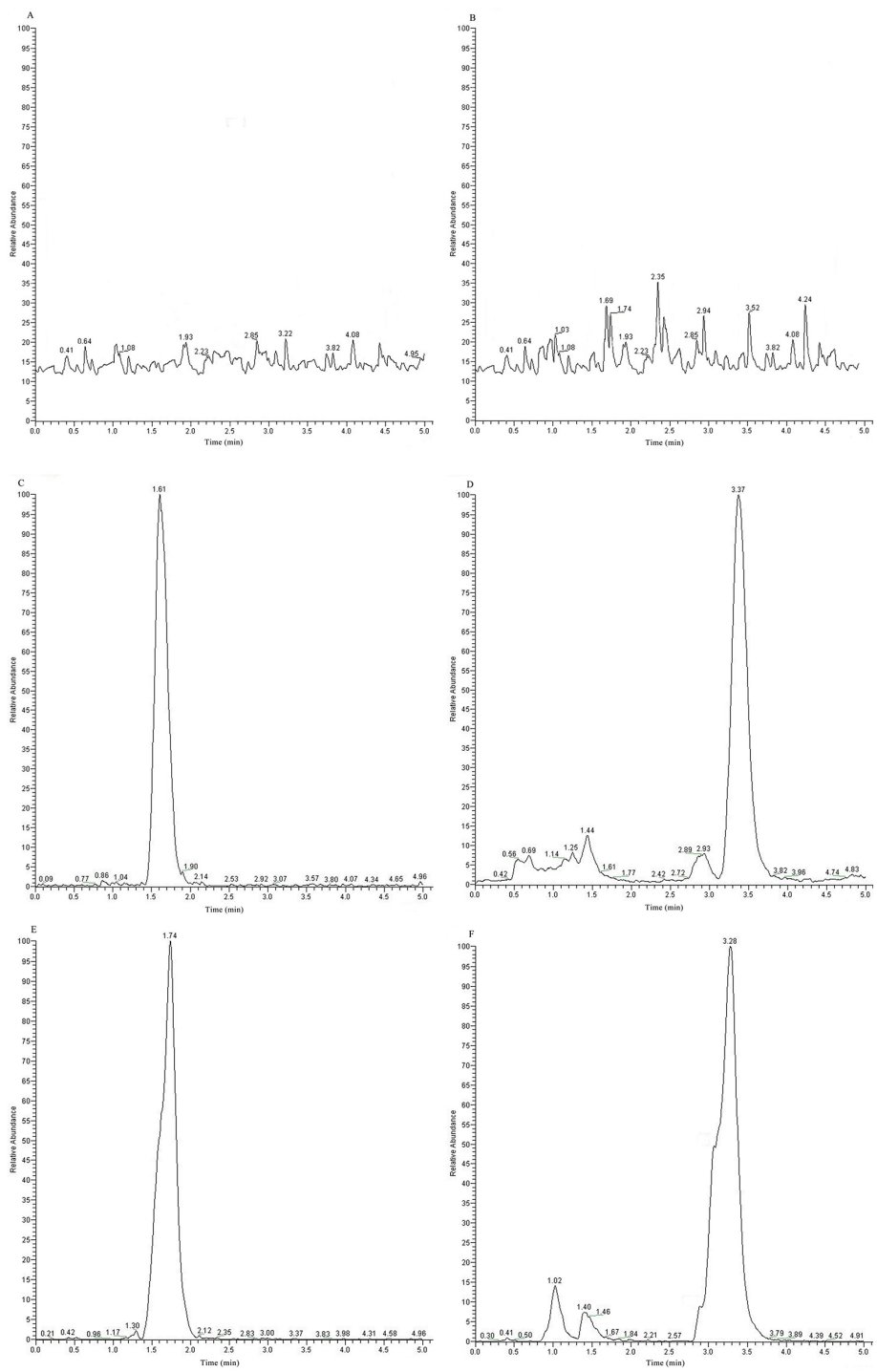

Figure 6: Representative LC-MS/MS chromatograms for GA and IS. Notes: (A) A blank sample detected with GA channel. (B) A blank sample detected with IS channel. (C) A blank sample spiked with GA. (D) A blank sample spiked with IS. (E) A random sample after administration of GA. (F) A random sample after administration of GA spiked with IS

Abbreviations: LC-MS/MS, high-performance liquid chromatography-tandem mass spectrometry; GA, glycyrrhetinic acid; IS, ursolic acid. 
Table 4: Standard curves, linear coefficients and linear ranges of GA in different bio-samples

\begin{tabular}{lccc}
\hline Bio-sample & Standard curve & ${\text { Linear coefficient } \mathbf{r}^{2}}^{\text {Linear range (ng/mL) }}$ \\
\hline Plasma of mice & $\mathrm{Y}=0.006 \mathrm{X}+0.059$ & 0.9991 & $4-6000$ \\
Heart & $\mathrm{Y}=0.011 \mathrm{X}+0.182$ & 0.9991 & $5-6000$ \\
Liver & $\mathrm{Y}=0.007 \mathrm{X}+0.217$ & 0.9994 & $4-6000$ \\
Spleen & $\mathrm{Y}=0.005 \mathrm{X}+0.199$ & 0.9991 & $4-6000$ \\
Lung & $\mathrm{Y}=0.007 \mathrm{X}+0.112$ & 0.9994 & $4-6000$ \\
Kidney & $\mathrm{Y}=0.005 \mathrm{X}+0.158$ & 0.9994 & $4-6000$ \\
\hline
\end{tabular}

Abbreviations: GA, glycyrrhetinic acid; $Y$, the peak area ratio of GA to IS; X, the concentration of GA.

and GA-LP, the GA concentration from Gal-GA-LP declined slowly, which indicated that the GA liposome could prolong the active time because the formulation was removed slowly from the circulation [28]. The pharmacokinetic parameters, including elimination halflife $\left(\mathrm{t}_{1 / 2 \mathrm{z}}\right)$, clearance $(\mathrm{CL})$, volume of distribution $\left(\mathrm{V}_{\mathrm{d}}\right)$, area under the curve of drug concentration-time curve $\left(\mathrm{AUC}_{0}\right.$ $\left.{ }_{\infty}\right)$, and mean residence time $\left(\mathrm{MRT}_{0-\infty}\right)$, were analyzed using DAS 2.0 software. The main pharmacokinetic parameters are summarized in Table 8.

We confirmed whether or not the Gal-modified GA liposome had a liver-targeting efficiency in vivo. We studied the distributions of GA in heart, liver, spleen, lung, and kidney of mice at various time points after the intravenous administration of GA-S, GA-LP, and GalGA-LP. Then, we tested GA concentrations in tissue samples and the results are shown in Figure 7B-7D. The pharmacokinetic $\left(\mathrm{AUC}_{0-\infty}\right.$ and $\left.\mathrm{C}_{\max }\right)$ and targeting parameters $(\mathrm{Re}, \mathrm{Te}$, and $\mathrm{Ce})$ are summarized in Table 9. The GA concentration from Gal-GA-LP in the liver was clearly higher than other tissues.

\section{DISCUSSION}

GA is an effective ingredient in treatment of hepatic dieases $[4,5]$. However, GA is lipophilic and cause sodium retension or potassium loss [10]. Recent researchers in this area have focused on receptor-mediated drug delivery systems based on liposomes. The active targeting can be achieved through introduction of a targeting ligand into liposomes. Thus, a novel galactosylated derivates modified liposomes are designed for selective targeting of hepatic cells which are over-expressing asialoglycoprotein receptor.

In our previous study, Gal was synthesized successfully under the condition of lipase-catalytic. We chose the cholesterol because cholesterol was one of the components of liposomes, which could enhance stability the galactosyl moiety in liposomes. Lactitol containing galactosyl residue showed a higher affinity for asialoglycoprotein receptor. Divinyl sebacate was chosen as a spacer part of link between cholesterol and lactitol, the carbon chain length of bivinyl sebacate can meet the spatial distance between the galactosyl residues and the liposome surface.

The particle size plays an important role on drug distribution in vivo. It has been reported that the diameter of liposomes ranging from 100-200nm can significantly accumulate in tumor tissue on account of permeability and retention effect [29]. With an increasing amount of Gal, we reasoned that the liver-targeting phenomenon might be better while the encapsulation efficiency decreased and the particle size increased. Taking this into account, we selected 5\% Gal. In our study, the particle size of GA-LP and Gal-GA-LP were less than $200 \mathrm{~nm}$. We found that the higher the value of the zeta potential, the more difficult the electrostatic repulsion among these particles, which made the particles more stable in the dispersal system [30].

For the in vitro release study, the release of GA-S was relatively rapid while the release of GA-LP and Gal-GA-LP were slow. These data indicated that the incorporation of Gal into the liposome probably did not destroy the structure of the liposome. GA release was observed in vitro up to $48 \mathrm{~h}$, and the data suggested that the application of liposomes would be increase the retention time of GA in the circulation and enhance the drug effects. The sustained release of GA revealed its applicability as a drug delivery system with continuous, slow release, and minimization of healthy tissue exposure when increasing the accumulation of therapeutic drugs in tumor sites.

The in vitro cellular uptake study was indicated that Gal-GA-LP might be transported into HepG2 cells by receptor-mediated endocytosis because of the Gal ligand, which specifically identified its receptor, and then exert its therapeutic effect after being released from the carrier. The cellular uptake results were in accordance with the results obtained by Guhagarkar et al [31-33]. The study showed that Gal-GA-LP is a promising targeting drug for hepatic diseases in the clinic.

The extraction methods of plasma and tissue samples were evaluated. The methods of protein precipitation (PPT), liquid-liquid extraction (LLE), and solid-phase extraction (SPE) were evaluated for the plasma and tissue preparations to establish a better method. PPT, including 
Table 5: Intra-day and Inter-day accuracy and precision of the method for determination of GA in biological samples

\begin{tabular}{|c|c|c|c|c|c|c|c|}
\hline \multirow[b]{2}{*}{$\begin{array}{l}\text { Biological } \\
\text { sample }\end{array}$} & \multirow[b]{2}{*}{ QC (ng/mL) } & \multicolumn{3}{|c|}{ Intra-day $(n=6)$} & \multicolumn{3}{|c|}{ Inter-day $(n=6)$} \\
\hline & & $\begin{array}{c}\text { Mean } \\
\text { concentration } \\
(\mathrm{ng} / \mathrm{mL}) \pm \\
\text { S.D. }\end{array}$ & $\begin{array}{c}\text { Accuracy } \\
\text { (R.E.\%) }\end{array}$ & $\begin{array}{l}\text { Precision } \\
\text { (R.S.D.\%) }\end{array}$ & $\begin{array}{c}\text { Mean } \\
\text { concentration } \\
(\mathbf{n g} / \mathbf{m L}) \pm \\
\text { S.D. }\end{array}$ & $\begin{array}{l}\text { Accuracy } \\
\text { (R.E.\%) }\end{array}$ & $\begin{array}{c}\text { Precision } \\
\text { (R.S.D.\%) }\end{array}$ \\
\hline \multirow[t]{3}{*}{ Plasma } & 25.00 & $25.19 \pm 1.02$ & 0.75 & 4.06 & $26.28 \pm 1.10$ & 5.13 & 4.17 \\
\hline & 800.00 & $\begin{array}{c}809.38 \pm \\
24.21\end{array}$ & 1.17 & 2.99 & $822.24 \pm 16.57$ & 2.78 & 2.02 \\
\hline & 2000.00 & $\begin{array}{c}1925.79 \pm \\
139.23\end{array}$ & -3.71 & 7.23 & $\begin{array}{c}2119.71 \pm \\
124.08\end{array}$ & 5.99 & 5.85 \\
\hline \multirow[t]{3}{*}{ Heart } & 25.00 & $25.62 \pm 1.01$ & 2.48 & 3.96 & $26.68 \pm 1.10$ & 6.72 & 4.11 \\
\hline & 800.00 & $\begin{array}{c}791.45 \pm \\
39.25\end{array}$ & -1.07 & 4.96 & $838.11 \pm 36.57$ & 4.76 & 4.36 \\
\hline & 2000.00 & $\begin{array}{c}2051.49 \pm \\
78.79\end{array}$ & 2.57 & 3.84 & $\begin{array}{c}2190.51 \pm \\
169.05\end{array}$ & 9.53 & 7.72 \\
\hline \multirow[t]{3}{*}{ Liver } & 25.00 & $25.41 \pm 1.28$ & 1.63 & 5.04 & $26.01 \pm 1.86$ & 4.02 & 7.14 \\
\hline & 800.00 & $\begin{array}{c}825.17 \pm \\
30.03\end{array}$ & 3.15 & 3.64 & $\begin{array}{c}845.68 \pm \\
31.87\end{array}$ & 5.71 & 3.77 \\
\hline & 2000.00 & $\begin{array}{c}1945.70 \pm \\
70.76\end{array}$ & -2.71 & 3.64 & $\begin{array}{c}2191.93 \pm \\
112.10\end{array}$ & 9.60 & 5.11 \\
\hline \multirow[t]{3}{*}{ Spleen } & 25.00 & $25.47 \pm 0.88$ & 1.87 & 3.44 & $24.54 \pm 1.56$ & -1.83 & 6.37 \\
\hline & 800.00 & $\begin{array}{c}779.13 \pm \\
20.48\end{array}$ & -2.61 & 2.63 & $\begin{array}{c}832.60 \pm \\
23.45\end{array}$ & 4.08 & 2.82 \\
\hline & 2000.00 & $\begin{array}{c}2126.29 \pm \\
209.11\end{array}$ & 6.31 & 9.83 & $\begin{array}{c}2189.88 \pm \\
157.19\end{array}$ & 9.49 & 7.18 \\
\hline \multirow[t]{3}{*}{ Lung } & 25.00 & $24.66 \pm 1.04$ & -1.37 & 4.21 & $25.63 \pm 1.73$ & 2.53 & 6.76 \\
\hline & 800.00 & $\begin{array}{c}779.78 \pm \\
26.37\end{array}$ & -2.53 & 3.38 & $\begin{array}{c}787.26 \pm \\
48.25\end{array}$ & -1.59 & 6.13 \\
\hline & 2000.00 & $\begin{array}{c}2049.59 \pm \\
189.36\end{array}$ & 2.48 & 9.24 & $\begin{array}{c}2142.81 \pm \\
138.66\end{array}$ & 7.14 & 6.47 \\
\hline \multirow[t]{3}{*}{ Kidney } & 25.00 & $25.85 \pm 1.28$ & 3.40 & 4.95 & $26.28 \pm 1.16$ & 5.11 & 4.41 \\
\hline & 800.00 & $\begin{array}{c}831.41 \pm \\
28.78\end{array}$ & 3.93 & 3.46 & $\begin{array}{c}853.46 \pm \\
29.21\end{array}$ & 6.68 & 3.42 \\
\hline & 2000.00 & $\begin{array}{c}2070.00 \pm \\
163.94\end{array}$ & 3.50 & 7.92 & $\begin{array}{c}2178.93 \pm \\
178.35\end{array}$ & 8.95 & 8.19 \\
\hline
\end{tabular}

Note: R.S.D. $(\%)=($ S.D. $/$ mean concentration $){ }^{*} 100 \%$; R.E. $(\%)=[(\text { mean concentration } / \mathrm{QC})-1]^{*} 100 \%$.

Abbreviations: GA, glycyrrhetinic acid; QC, quality control samples; R.E., relative error; R.S.D., relative standard deviation; S.D., standard deviation.

methanol, alcohol, and acetonitrile, failed to sufficiently remove endogenous interference, and SPE showed poor reproducibility due to the number of operating steps. The LLE method with various extracting solvents, including chloroform, ethyl acetate, and n-hexane, was investigated and evaluated for acceptable extraction recovery and matrix effect. Ethyl acetate with no concentrationdependent extraction recovery was adopted.

The data of pharmacokinetic parameters were showed the pharmacokinetic behaviors of GA in GAS, GA-LP, and Gal-GA-LP. The elimination half-lives $\left(\mathrm{t}_{1 / 2 \mathrm{z}}\right)$ of GA-LP $(5.819 \mathrm{~h})$ and Gal-GA-LP $(7.487 \mathrm{~h})$ were 
Table 6: The extraction recovery and matrix effect of the method for determination of GA in biological samples $(\mathbf{n}=6)$

\begin{tabular}{|c|c|c|c|c|c|}
\hline Sample & QC $(n g / m L)$ & $\begin{array}{c}\text { Extraction recovery }(\%, \\
\text { mean } \pm \text { S.D. })\end{array}$ & $\begin{array}{c}\text { R.S.D. } \\
(\%)\end{array}$ & $\begin{array}{c}\text { Matrix effect }(\%, \text { mean } \pm \\
\text { S.D.) }\end{array}$ & R.S.D. (\%) \\
\hline \multirow[t]{3}{*}{ Plasma } & 25.00 & $84.33 \pm 3.20$ & 3.80 & $87.98 \pm 4.56$ & 5.19 \\
\hline & 800.00 & $78.75 \pm 3.37$ & 4.28 & $91.43 \pm 5.70$ & 6.24 \\
\hline & 2000.00 & $84.75 \pm 2.32$ & 2.74 & $93.67 \pm 5.20$ & 5.55 \\
\hline \multirow[t]{3}{*}{ Heart } & 25.00 & $83.04 \pm 5.25$ & 6.32 & $90.30 \pm 5.97$ & 6.62 \\
\hline & 800.00 & $84.31 \pm 4.79$ & 5.68 & $91.62 \pm 4.40$ & 4.81 \\
\hline & 2000.00 & $88.70 \pm 2.96$ & 3.34 & $92.41 \pm 4.37$ & 4.73 \\
\hline \multirow[t]{3}{*}{ Liver } & 25.00 & $85.45 \pm 6.80$ & 7.96 & $91.25 \pm 6.47$ & 7.09 \\
\hline & 800.00 & $82.64 \pm 5.15$ & 6.23 & $92.56 \pm 5.48$ & 5.92 \\
\hline & 2000.00 & $87.84 \pm 6.52$ & 7.42 & $93.19 \pm 4.19$ & 4.50 \\
\hline \multirow[t]{3}{*}{ Spleen } & 25.00 & $82.25 \pm 6.38$ & 7.76 & $92.68 \pm 3.32$ & 3.59 \\
\hline & 800.00 & $80.66 \pm 6.73$ & 8.34 & $91.85 \pm 4.85$ & 5.28 \\
\hline & 2000.00 & $86.50 \pm 3.47$ & 4.02 & $90.77 \pm 3.82$ & 4.21 \\
\hline \multirow[t]{3}{*}{ Lung } & 25.00 & $79.37 \pm 7.64$ & 9.63 & $91.76 \pm 4.26$ & 4.64 \\
\hline & 800.00 & $84.22 \pm 4.75$ & 5.64 & $90.49 \pm 2.91$ & 3.22 \\
\hline & 2000.00 & $87.45 \pm 2.90$ & 3.31 & $92.14 \pm 3.94$ & 4.28 \\
\hline \multirow[t]{3}{*}{ Kidney } & 25.00 & $80.11 \pm 6.10$ & 7.61 & $91.91 \pm 5.33$ & 5.80 \\
\hline & 800.00 & $81.93 \pm 6.40$ & 7.82 & $92.96 \pm 3.99$ & 4.30 \\
\hline & 2000.00 & $86.41 \pm 2.62$ & 3.03 & $94.01 \pm 3.86$ & 4.11 \\
\hline
\end{tabular}

Note: R.S.D. $(\%)=($ S.D. $/$ mean concentration $){ }^{*} 100 \%$.

Abbreviations: GA, glycyrrhetinic acid; QC, quality control samples; R.S.D., relative standard deviation; S.D., standard deviation.

longer than GA-S (5.422 h). In addition, the mean plasma clearances (CL) for GA-LP $\left(0.976 \mathrm{~L} \mathrm{~h}^{-1} \mathrm{~kg}^{-1}\right)$ and Gal-GALP $\left(0.662 \mathrm{~L} \mathrm{~h}^{-1} \mathrm{~kg}^{-1}\right)$ were less than GA-S $\left(1.929 \mathrm{~L} \mathrm{~h}^{-1}\right.$ $\left.\mathrm{kg}^{-1}\right)$. These results indicated that GA in liposomes was cleared slowly from the blood. The relatively large values of the distribution volume $\left(\mathrm{V}_{\mathrm{d}}\right)$ of GA-LP $\left(8.149 \mathrm{~L} \mathrm{~kg}^{-1}\right)$ and Gal-GA-LP (7.119 $\mathrm{L} \mathrm{kg}^{-1}$ ), when compared with GA-S (13.953 $\mathrm{L} \mathrm{kg}^{-1}$ ), suggested that GA in liposomes could be easily distributed into tissues, which was beneficial to treat hepatic diseases. The areas under the curve of drug concentration $\left(\mathrm{AUC}_{0-\infty}\right.$ ) for GA-LP and Gal-GA-LP were 1.90-fold and 2.79-fold, respectively. These results indicated that Gal-GA-LP circulated longer in the blood than GA-S. Moreover, when compared with GA-S, higher mean residence times $\left(\mathrm{MRT}_{0-\infty}\right)$ of GA-LP (1.14-fold) and Gal-GA-LP (1.48-fold) indicated that GA liposomes prolong drug circulation in the blood [34].

Furthermore, the distributions study showed that GA concentration from Gal-GA-LP in the liver was clearly higher than other tissues, indicating that the Galmodified liposome delivered GA mainly to the liver after the intravenous administration and demonstrated that
GA liposomes modified with galactosylated lipid had enormous potential as a liver-targeting drug carrier [35, 36]. The $\mathrm{AUC}_{0-\infty}$ of GA-LP (2.20-fold) and Gal-GA-LP (4.75-fold) was higher than GA-S in the liver, which suggested that Gal-modified GA liposomes contribute to enhance liver-targeting value. In addition, the target evaluations of three important parameters (Re, Te, and $\mathrm{Ce}$ ) were calculated. Compared with GA-LP, the Re of GalGA-LP was the highest in the liver, which demonstrated that the release of GA to the liver was increased by Galmodified liposomes. Compared with GA-S and GALP, Gal-GA-LP had outstanding liver-targeting with Te (48.193\%) and Ce (2.796). The bio-distribution study indicated that Gal-GA-LP had better liver-targeting ability. These bio-distribution results were in agreement with those obtained by Biessen [37], which illustrated that galactosylated moieties are optimally recognized by liver. Thus, Gal-GA-LP could be enhanced for its bioavailability and targeted to the liver after intravenous injection.

In conclusion, GA liposomes modified with the liver-targeting ligand of Gal were prepared. The dynamic light scattering results showed that the spherical structure 
Table 7: Stability of GA in plasma and tissue samples under different storage conditions $(n=6)$

\begin{tabular}{|c|c|c|c|c|c|c|c|}
\hline \multirow{2}{*}{ Storage condition } & \multirow{2}{*}{ QC (ng/mL) } & \multicolumn{6}{|c|}{ R.S.D. (\%) } \\
\hline & & Plasma & Heart & Liver & Spleen & Lung & Kidney \\
\hline \multirow[t]{3}{*}{$\begin{array}{l}\text { Room temperature }\left(25^{\circ} \mathrm{C}\right) \\
\text { for } 24 \mathrm{~h}\end{array}$} & 25.00 & 5.58 & 3.50 & 5.30 & 5.40 & 6.07 & 6.71 \\
\hline & 800.00 & 6.81 & 6.03 & 5.90 & 7.23 & 6.89 & 5.87 \\
\hline & 2000.00 & 10.28 & 10.93 & 10.35 & 6.52 & 8.54 & 6.72 \\
\hline \multirow[t]{3}{*}{$\begin{array}{l}\text { Frozen-thaw cycles at } \\
-20^{\circ} \mathrm{C}\end{array}$} & 25.00 & 5.73 & 5.28 & 4.66 & 4.01 & 6.17 & 5.20 \\
\hline & 800.00 & 7.07 & 5.03 & 5.24 & 7.05 & 8.02 & 7.44 \\
\hline & 2000.00 & 9.70 & 10.57 & 9.01 & 7.68 & 9.17 & 9.07 \\
\hline \multirow[t]{3}{*}{$\begin{array}{l}\text { Frozen }\left(-20^{\circ} \mathrm{C}\right) \text { for } 1 \\
\text { month }\end{array}$} & 25.00 & 4.46 & 4.72 & 5.63 & 4.60 & 5.80 & 5.02 \\
\hline & 800.00 & 5.10 & 4.23 & 9.10 & 5.06 & 4.73 & 4.82 \\
\hline & 2000.00 & 8.87 & 12.70 & 6.41 & 9.40 & 7.88 & 8.17 \\
\hline
\end{tabular}

Note: R.S.D. $(\%)=($ S.D. $/$ mean concentration $){ }^{*} 100 \%$.

Abbreviations: GA, glycyrrhetinic acid; QC, quality control samples; R.S.D., relative standard deviation.
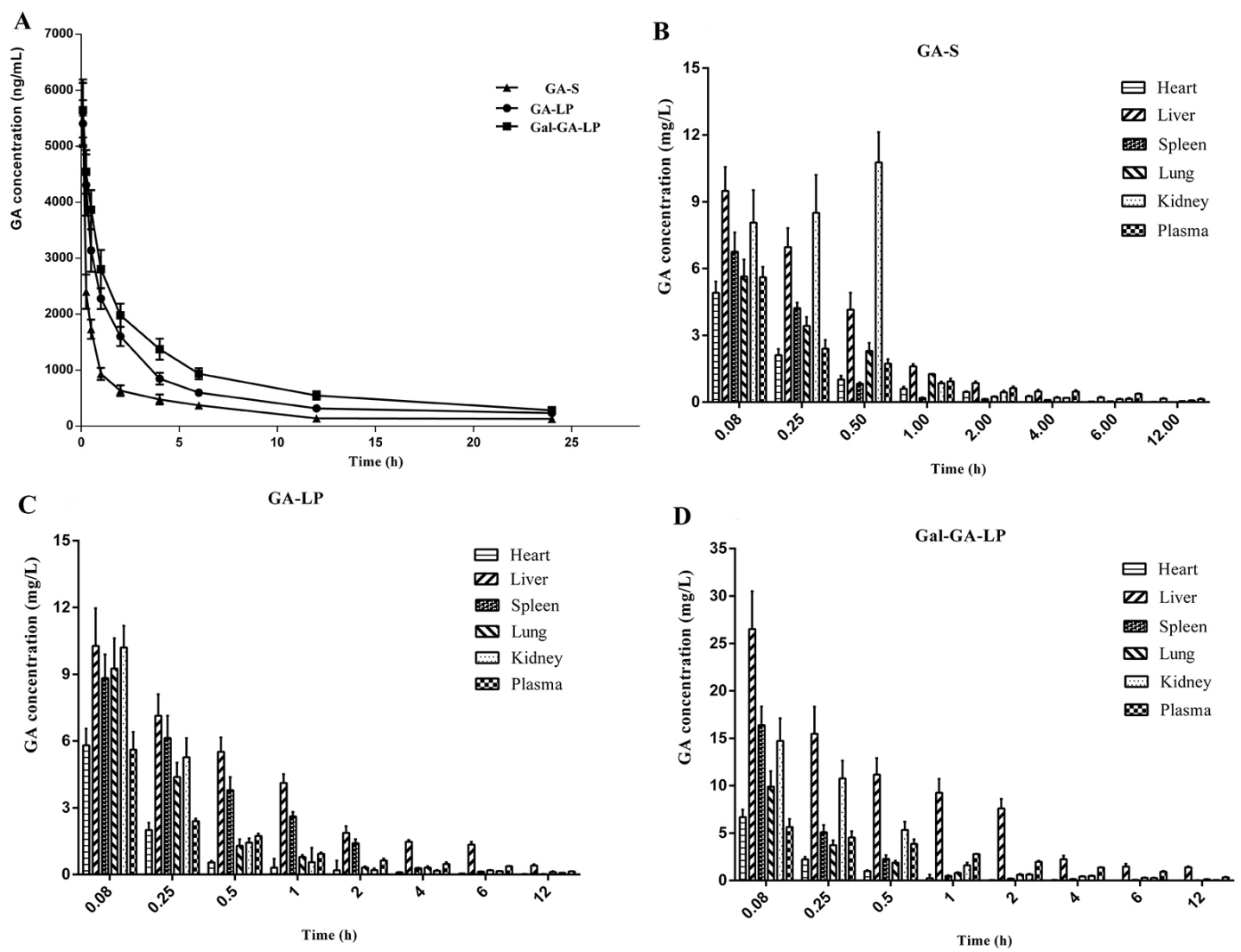

Figure 7: Mean plasma concentration of GA in mice after intravascular administration of GA-S, GA-LP, and GalGA-LP and distributions of GA in different organs at various time points after intravascular administration of GA-S, GA-LP, and Gal-GA-LP. Note: Data shown represent the mean \pm S.D.

Abbreviations: GA, glycyrrhetinic acid; GA-S, glycyrrhetinic acid solvent; GA-LP, glycyrrhetinic acid liposomes; Gal-GA-LP, glycyrrhetinic acid liposomes modified with liver-targeting ligand of galactosylated derivative. 
Table 8: Comparisons of plasma pharmacokinetic parameters of GA-S, GA-LP, and Gal-GA-LP after i.v. administration (mean \pm S.D., $n=5)$

\begin{tabular}{|c|c|c|c|}
\hline Parameters & GA-S & GA-LP & Gal-GA-LP \\
\hline$t_{1 / 2 z}(h)$ & $5.422 \pm 2.632$ & $5.819 \pm 0.445^{*}$ & $7.487 \pm 2.953^{*}$ \\
\hline $\mathrm{CL}\left(\mathrm{L} \mathrm{h}^{-1} \mathrm{~kg}^{-1}\right)$ & $1.929 \pm 0.446$ & $0.976 \pm 0.099^{*}$ & $0.662 \pm 0.059^{*}$ \\
\hline $\mathrm{V}_{\mathrm{d}}\left(\mathrm{L} \mathrm{kg}^{-1}\right)$ & $13.953 \pm 3.000$ & $8.149 \pm 0.280^{*}$ & $7.119 \pm 2.869^{*}$ \\
\hline $\mathrm{AUC}_{0-\mathrm{t}}\left(\mathrm{ug} \mathrm{h} \mathrm{L^{-1 }}\right)$ & $7373.510 \pm 2243.468$ & $15470.120 \pm 1453.593^{*}$ & $21524.930 \pm 2297.092^{* *}$ \\
\hline $\mathrm{AUC}_{0-\infty}(\mathrm{ug} \mathrm{h} \mathrm{L}-1)$ & $8493.645 \pm 2238.985$ & $16110.572 \pm 1634.666^{*}$ & $23731.974 \pm 2143.466^{* *}$ \\
\hline $\mathrm{MRT}_{0-\mathrm{t}}(\mathrm{h})$ & $3.999 \pm 1.786$ & $6.248 \pm 0.054^{*}$ & $6.616 \pm 0.980^{*}$ \\
\hline $\mathrm{MRT}_{0-\infty}(\mathrm{h})$ & $6.366 \pm 2.628$ & $7.276 \pm 0.257^{*}$ & $9.440 \pm 2.630^{*}$ \\
\hline
\end{tabular}

Notes: Data shown represent the mean \pm S.D., ${ }^{*}$, when compared with GA-S, $P<0.05$; ${ }^{* *}$, when compared with GA-S and GA-LP, $P<0.05$.

Abbreviations: GA-S, glycyrrhetinic acid solvent; GA-LP, glycyrrhetinic acid liposomes; Gal-GA-LP, glycyrrhetinic acid liposomes modified with liver-targeting ligand of galactosylated derivative; $\mathrm{T}_{1 / 2} \mathrm{z}$, terminal elimination half-life; CL, apparent tissue clearance; Vd, apparent volume of distribution; AUC, area under concentration-time curve; MRT, mean residence time; S.D., standard deviation; i.v., intravascular.

Table 9: Pharmacokinetic parameters and targeting parameters of GA-S, GA-LP, Gal-GA-LP in plasma and various tissues of mice after i.v. administration $(n=5)$

\begin{tabular}{llcccccc}
\hline Sample & Parameters & Heart & Liver & Spleen & Lung & Kidney & Plasma \\
\hline GA-S & AUC $\left(\mu \mathrm{g} \mathrm{h} \mathrm{L}^{-1}\right)$ & 3471.481 & 9448.575 & 3217.687 & 4942.941 & 9819.824 & 7373.510 \\
& $\mathrm{C}_{\max }\left(\mu \mathrm{g} \mathrm{L}^{-1}\right)$ & 4907.228 & 9485.357 & 6760.000 & 5638.488 & 10764.400 & 5608.573 \\
& Te $(\%)$ & 9.070 & 24.687 & 8.407 & 12.915 & 25.657 & 19.265 \\
GA-LP & $\mathrm{AUC}\left(\mu \mathrm{g} \mathrm{h} \mathrm{L}^{-1}\right)$ & 2654.329 & 20746.629 & 9526.295 & 5918.741 & 5441.211 & 15470.120 \\
& $\mathrm{C}_{\max }\left(\mu \mathrm{g} \mathrm{L}^{-1}\right)$ & 5806.441 & 10269.646 & 8819.786 & 9253.503 & 10201.204 & 5403.583 \\
& $\mathrm{Re}$ & 0.765 & 2.196 & 2.961 & 1.197 & 0.554 & 2.098 \\
& $\mathrm{Te}(\%)$ & 4.442 & 34.718 & 15.942 & 9.905 & 9.106 & 25.888 \\
& $\mathrm{Ce}$ & 1.183 & 1.083 & 1.305 & 1.641 & 0.948 & 0.963 \\
Gal-GA-LP & $\mathrm{AUC}\left(\mu \mathrm{g} \mathrm{h} \mathrm{L}^{-1}\right)$ & 2435.328 & 44901.029 & 6030.967 & 7074.443 & 11202.158 & 21524.930 \\
& $\mathrm{C}_{\max }\left(\mu \mathrm{g} \mathrm{L}^{-1}\right)$ & 2479.942 & 26525.004 & 16382.000 & 9888.715 & 14728.002 & 5643.000 \\
& $\mathrm{Re}$ & 0.702 & 4.752 & 1.874 & 1.431 & 1.141 & 2.919 \\
& $\mathrm{Te}(\%)$ & 2.614 & 48.193 & 6.473 & 7.593 & 12.024 & 23.103 \\
& $\mathrm{Ce}$ & 0.505 & 2.796 & 2.423 & 1.754 & 1.368 & 1.006 \\
\hline
\end{tabular}

Abbreviations: GA-S, glycyrrhetinic acid solvent; GA-LP, glycyrrhetinic acid liposomes; Gal-GA-LP, glycyrrhetinic acid liposomes modified with liver-targeting ligand of galactosylated derivative; AUC, area under concentration-time curve; Re, Relative intake rate; Te, Targeting efficiency; Ce, Peak concentration ratio; i.v., intravascular.

of Gal-GA-LP was approximately $170 \mathrm{~nm}$ and had good dispersion. Gal-GA-LP also exhibited high EE and low LR under physiologic conditions. Based on in vitro studies, the data demonstrated that the application of liposome formulation could prolong GA release and Gal was a safe drug carrier for targeted drug delivery to hepatocytes. In addition, the cellular uptake experiments illustrated that GA loaded with galactosylated moieties were ideal receptors and could be recognized by HepG2 cells. Furthermore, a LC-MS/MS method for quantifiable determination of GA in plasma and tissues was established successfully. Based on pharmacokinetic and bio-distribution studies, Gal-GA-LP showed better delivery efficiency and low cytotoxicity under intravenous injection. As a result, Gal-GA-LP may have huge potential as a promising nanocarrier in future clinical therapeutics. 
Table 10: The experimental design of hemolysis test

\begin{tabular}{|c|c|c|c|c|c|c|c|c|}
\hline Tube number & 1 & 2 & 3 & 4 & 5 & 6 & 7 & 8 \\
\hline $2 \%$ erythrocyte standard suspension $(\mathrm{mL})$ & 2.5 & 2.5 & 2.5 & 2.5 & 2.5 & 2.5 & 2.5 & 0 \\
\hline Physiological saline (mL) & 2.4 & 2.3 & 2.2 & 2.0 & 1.8 & 2.5 & 0 & 4.3 \\
\hline Distilled water (mL) & 0 & 0 & 0 & 0 & 0 & 0 & 2.5 & 0 \\
\hline Sample (GA-S, GA-LP or Gal-GA-LP, mL) & 0.1 & 0.2 & 0.3 & 0.5 & 0.7 & 0 & 0 & 0.7 \\
\hline
\end{tabular}

Abbreviations: GA-S, glycyrrhetinic acid solvent; GA-LP, glycyrrhetinic acid liposomes; Gal-GA-LP, glycyrrhetinic acid liposomes modified with liver-targeting ligand of galactosylated derivative.

\section{MATERIALS AND METHODS}

\section{Materials}

GA (assay 97.0\%) was supplied by the China Resources Sanjiu Medical \& Pharmaceutical (Shanghai, China). Ursolic acid (assay 99.2\%, the internal standard [IS]) was purchased from the National Institutes for Food and Drug Control ([NIFDC], Guangzhou, China). Gal was synthesized by a non-aqueous enzymatic reaction in our laboratory. Egg phosphatidylcholine ([EPC], assay 98.0\%) was purchased from Lipoid Co., Ltd. (Ludwigshafen, Germany). Cholesterol ([CH], assay 98\%) was purchased from Advanced Vehicle Technology Pharmaceuticala. (Shanghai, China). Roswell Park Memorial Institute (RPMI)-1640 medium and trypsin solution $(0.25 \%)$ were supplied by Thermo (Boston, MA, USA). Fetal bovine serum (FBS) was purchased from Hyclone (Logan, UT, USA). The hepatocellular carcinoma (HepG2) cell line was provided by the Institute of Biochemistry and Cell Biology, CAS (Shanghai, China). Methanol, ethanol, ammonium acetate, and ethyl acetate were purchased from Guangzhou Chemical Reagent Factory (Guangzhou, China) and were of at least analytical grade. HPLC or LC$\mathrm{MC} / \mathrm{MS}$ reagents were filtered through a $0.22 \mu \mathrm{m}$ filter before analysis. Methanol, ethanol, ethyl acetate, and the other reagents in liquid-liquid extraction were of analytical grade and used without further purification. Watsons' water was used in all experiments.

\section{GA-S}

Sodium hydroxide $(0.1 \mathrm{~mol} / \mathrm{L})$ was diluted with saline to adjust to a $\mathrm{pH}=8.2$, then $7.8 \mathrm{mg}$ of $\mathrm{GA}$ was dissolved in $5 \mathrm{~mL}$ of sodium hydroxide solution $(\mathrm{pH}=8.2)$ to prepare the desired concentration.

\section{Stock solution}

Stock solutions of GA and IS were prepared at 0.04 $\mathrm{mg} / \mathrm{mL}$ by dissolving $2 \mathrm{mg}$ in $50 \mathrm{~mL}$ of methanol, then stored at $-20^{\circ} \mathrm{C}$. Then, an amount of IS stock solution was diluted with methanol to make a concentration of $1 \mu \mathrm{g} /$ $\mathrm{mL}$ and stored at $-20^{\circ} \mathrm{C}$. Phosphate buffered saline ([PBS], $\mathrm{pH}=7.4$ ) was prepared with $0.136 \mathrm{~g}$ of monopotassium phosphate and $7.9 \mathrm{~mL}$ of $0.1 \mathrm{~mol} / \mathrm{L}$ sodium hydroxide diluted in $100 \mathrm{~mL}$ of water, then filtered through a $0.22 \mu \mathrm{m}$ filter without particulate matter.

\section{Animals}

Kunming mice (18-25 g; male and female mice in equal numbers) and New Zealand white rabbits (1.9-2.1 $\mathrm{kg}$ ) were obtained from the Laboratory Animal Center of Guangzhou University of Chinese Medicine (Guangzhou, China). The animals were kept in cages under uniform experimental conditions (temperature, $25 \pm 2^{\circ} \mathrm{C}$; humidity, $60 \pm 5 \%$, dark-light cycle, $12 \mathrm{~h}$ ). Food and water were freely available. The experiments involving the care and use of laboratory animals were conducted in strict accordance with National Institutes of Health guidelines [38] and the China National Institutes of Health.

\section{Preparation of modification of GA-LP and Gal- GA-LP}

Gal-GA-LP was prepared using the thin-film dispersion method. In brief, EPC, $\mathrm{CH}$, and GA (weight: $28.2,8.2$, and $4.18 \mathrm{mg}$, respectively) and Gal (5\% of EPC, molar ratio) were dissolved in $5 \mathrm{~mL}$ of chloroform to form a mixed solution, then the organic solvent was removed under reduced pressure at $36-38^{\circ} \mathrm{C}$ by rotary evaporation to form a thin film on the inner walls of the round-bottomed flask. The vacuum was applied for $1 \mathrm{~h}$ to ensure total removal of any solvent trace. Glucose and mannitol $(1: 1, \mathrm{w} / \mathrm{w})$ were dissolved in PBS $(\mathrm{pH}=7.4)$. The lipid film was then hydrated with $5 \mathrm{~mL}$ of PBS $(\mathrm{pH}=7.4)$ at $55^{\circ} \mathrm{C}$ by rotation $(180 \mathrm{r} / \mathrm{min} \times 1 \mathrm{~h})$ to form Gal-GALP. The injection of obtained liposomes was applied by probing ultrasonication for $10 \mathrm{~min}$ at $220 \mathrm{~W}$, then thricefiltered through a polycarbonate filter with $0.22 \mu \mathrm{m}$ pores. To obtain a homogenous suspension, the injection was frozen at $-20^{\circ} \mathrm{C}$ for $1 \mathrm{~h}$, then dissolved in an ultrasonic water bath, repeated 3 times, then filtered with $0.22 \mu \mathrm{m}$ pores 3 times. The final liposomal vesicles were filled into penicillin bottles $(10 \mathrm{~mL})$, and pre-frozen at $-80^{\circ} \mathrm{C}$ for $8 \mathrm{~h}$. Gal-GA-LP suspensions were transferred to a freeze drier 
for $24 \mathrm{~h}$ to ensure the physical stability of the ultimate product. Lyophilized Gal-GA-LP powders were obtained. The procedure for producing conventional liposomes (GA-LP) without supplemental Gal were similar to GalGA-LP, but the weight of EPC, CH, and GA was 28.2, 9.4, and $4.2 \mathrm{mg}$, respectively.

In the current study, a single-factor method was used to determine optimal conditions. The proportion of GA to blank liposomes ranged from 1:10-1:6. The molar ratio of Gal: EPC ranged from 3\%-9\%. The types of cryoprotectant contained mannitol, trehalose, sucrose, glucose, glucosemannitol, glucose-trehalose, sucrose-trehalose, sucroseglucose, mannitol-trehalose, and mannitol-sucrose. The proportion of cryoprotectant and EPC ranged from 4:112:1 and a comparison between the ethanol injection and thin-film dispersion methods was made.

\section{Physicochemical characterizations of liposomes}

\section{Appearance}

The GA-LP and Gal-GA-LP suspensions were semi-transparent white solutions with a visible sky-blue opalescence. The particle shapes were observed under a transmission electron microscope (TEM).

\section{Particle size, polydispersity index, and distribution}

A suitable amount of lyophilized GA-LP and GalGA-LP samples were dispersed in $5 \mathrm{~mL}$ of deionized water, and $3 \mathrm{~mL}$ of the solution was filled in a sample cell for detection purposes. The particle size, polydispersity index (PDI), and zeta-potential (ZP) of Gal-GA-LP and GA-LP were determined using a Zetasizer Nano ZS90 analyzer (Malvern Instruments, UK). Ensuring the reproducibility of experimental measuring conditions, the samples were adapted to the instrument systematically and automatically with a fixed angle of $90^{\circ}$ to the incident light. The data were collected every $3 \mathrm{~min}$.

\section{Encapsulation efficiency (EE \%) and drug loading (DL} \%)

Encapsulation efficiency (EE \%) was expressed as the ratio of liposome-encapsulated drugs $\left(\mathrm{E}_{\text {drug }}\right)$ to the total amount of drug $\left(\mathrm{T}_{\text {drug }}\right)$ in the liposome preparation, and was measured using the Sephadex-50 filtration method. Drug loading (DL \%) was expressed as the percentage of liposome-encapsulated drugs to the total amount of liposome-containing drug. EE \% and DL \% were calculated following Equations 1 and 2:

$$
\begin{aligned}
& \mathrm{EE} \%=\mathrm{E}_{\text {drug }} / \mathrm{T}_{\text {drug }} \times 100 \% \quad \text { Eq. } 1 \\
& \mathrm{DL} \%=\mathrm{E}_{\text {drug }} /\left(\mathrm{T}_{\text {drug }}+\mathrm{T}_{\text {liposomes }}\right) \times 100 \% \\
& \text { Eq. } 2
\end{aligned}
$$

where $\mathrm{E}_{\text {drug }}$ is the weight of drug being encapsulated in the liposomes, $\mathrm{T}_{\text {drug }}$ is the weight of the total amount of charged drug, and $\mathrm{T}_{\text {liposomes }}$ is the weight of the total amount of blank liposomes.

To remove unentrapped drug completely, $\mathrm{E}_{\text {drug }}$ was evaluated after collecting the incorporated liposomes from
$0.5 \mathrm{~mL}$ of the liposome suspension through a Sephadex G-50 mini-column $(1.3 \times 22 \mathrm{~cm})$. Ten milliliters of the water fraction containing the liposomes of encapsulated drug was collected. To calculate the $\mathrm{E}_{\text {drug }}, 0.2 \mathrm{~mL}$ of the collected encapsulated drug fraction was disrupted by the addition of $0.8 \mathrm{~mL}$ of methanol to form a clear solution. Similarly, to determine the $\mathrm{T}_{\text {drug }}$ in the liposome suspension, $0.9 \mathrm{~mL}$ of methanol was added to $0.1 \mathrm{~mL}$ of the GA liposome suspension to form a limpid solution. The concentrations of $\mathrm{E}_{\text {drug }}$ and $\mathrm{T}_{\text {drug }}$ were measured by HPLC analysis.

For the quantitative determination of $\mathrm{GA}$, a reverse HPLC system was applied containing P680 HPLC pumps, an ASI-100 autosampler (Dionex, Sunnyvale, CA, USA), a UV detector (PDA-100 Photodiode Array; Dionex), and a BDS HYPERSIL C18 column (5 $\mu \mathrm{m}, 250 \times 4.6$ $\mathrm{mm}$; Thermo Fisher Scientific Biological Chemical Co., Ltd.) The mobile phase was methanol-1 \% acetic acid (89:11 [v/v]). The samples were determined at $254 \mathrm{~nm}$ by injecting a $10 \mu \mathrm{L}$ volume onto the column with a flow rate of $1 \mathrm{~mL} \cdot \mathrm{min}^{-1}$.

\section{In vitro drug release study}

GA release from Gal-GA-LP, GA-LP, and GA-S was determined using the dialysis bag method. Lyophilized GA-LP, Gal-GA-LP powder, and GA-S containing $8 \mathrm{mg}$ of GA were dissolved in $4 \mathrm{~mL}$ of PBS. Then, the solution was placed in dialysis bags (Thermo, USA). The bags were then put in $1000 \mathrm{~mL}$ beakers containing $500 \mathrm{~mL}$ of PBS buffer (adjusting $0.1 \mathrm{~mol}$ to $\mathrm{pH} 7.4$ ) under sinking conditions $\left(100 \mathrm{rpm}, 37^{\circ} \mathrm{C} \pm 0.5^{\circ} \mathrm{C}\right)$. The release buffer $(2.5$ $\mathrm{mL}$ ) was taken from the beaker at a pre-determined time $(0.5,1,2,4,6,9,12,24,36$, and $48 \mathrm{~h})$ and refilled with the same amount of fresh medium at given time intervals. The supernatant $(20 \mu \mathrm{L})$ was then injected directly into the HPLC system and the release of GA was analyzed. The released profiles were plotted. The accumulated release of GA-S, GA-LP, and Gal-GA-LP were calculated by the following formulas [39].

$$
\begin{aligned}
& \mathrm{C}_{1}{ }^{\prime}=\mathrm{C}_{1} \quad \text { Eq. } 3 \\
& \mathrm{C}_{i+1}{ }^{\prime}=\mathrm{C}_{\mathrm{i}+1}-\left(\mathrm{V}-\mathrm{V}_{\mathrm{i}}\right)^{*} \mathrm{C}_{\mathrm{i}} / \mathrm{V} \quad \text { Eq.4 }
\end{aligned}
$$

where $\mathrm{C}_{i}$ is the GA concentration of each sample (GA-S, GA-LP, and Gal-GA-LP) at pre-determined time intervals, $\mathrm{C}_{1}{ }^{\prime}$ is the increase of drug concentration during each time interval, $\mathrm{V}$ is the total volume of the released buffer, and $\mathrm{V}_{i}$ is the volume of each sample at pre-determined time intervals.

\section{Stability}

Owing to the permeability of liposome membranes, the drug content was leaked from the liposome membrane within a period of time, which resulted in a decreasing encapsulation rate. The leakage rate (LR \%) was a significant index to measure the stability of liposomes. 
According to the guidelines of the International Conference on Harmonisation [40], the stability studies of Gal-GA-LP, GA-LP, and GA-S were carried out under the following conditions: (1) temperature $\left(25^{\circ} \mathrm{C} \pm 2^{\circ} \mathrm{C}\right)$ and relative humidity $(60 \% \pm 5 \%)$ for 2 weeks; (2) temperature $\left(25^{\circ} \mathrm{C} \pm 2^{\circ} \mathrm{C}\right)$ for 1,2 , and 3 months; and (3) temperature $\left(4^{\circ} \mathrm{C} \pm 1^{\circ} \mathrm{C}\right)$ for 3 and 6 months. The stored samples were measured for the EE \%. The LR (\%) was calculated according to Equation 5:

$$
L R(\%)=\left(E_{i}-E_{p}\right) / E_{i} \times 100 \% \quad \text { Eq. } 5
$$

where $\mathrm{EE}_{\mathrm{i}}$ is the encapsulation efficiency of the initial time and $\mathrm{EE}_{\mathrm{p}}$ is the encapsulation efficiency of a predetermined time.

\section{Hemolysis testing}

This method of safe drug carriers has been reported [41]. The blood of New Zealand white rabbits was used to test the hemolysis effect of GA-S, GA-LP, and Gal-GA-LP. Blood samples $(10 \mathrm{~mL})$ were collected in heparinized test tubes and added to normal saline $(10 \mathrm{~mL})$, then vortexed for $1 \mathrm{~min}$. The mixture was subsequently centrifuged at 1500 $\mathrm{rpm}$ for $15 \mathrm{~min}$. The sedimented erythrocytes were collected, thrice-washed with saline $(10 \mathrm{~mL})$, and centrifuged repeatedly until the supernatant was no longer red [42]. Erythrocyte pellets $(2 \mathrm{~mL})$ were transferred to saline $(98$ $\mathrm{mL}$ ) to prepare a $2 \%$ erythrocyte standard suspension. GA$\mathrm{S}$, GA-LP, and Gal-GA-LP were dissolved in physiologic saline at a concentration of $4 \mathrm{mg} / \mathrm{mL}$ Twenty-four glass tubes were prepared and divided into three groups (GA-S, GALP, and Gal-GA-LP). The individuals of each group were numbered $1,2,3,4,5,6,7$, and 8 , as follows: tubes $1-5$ (hemolysis of test samples); tube 6 (negative control); tube 7 (positive control); and tube 8 (reference of test sample [GA-S, GA-LP, or Gal-GA-LP]). The experimental design of hemolysis test was shown in Table 10. After blending, all the tubes were incubated at $37^{\circ} \mathrm{C}$ and observed at baseline after $6 \mathrm{~h}$. Then, the suspension in each tube was remixed lightly after $24 \mathrm{~h}$ to observe agglutination of red cells.

\section{In vitro cellular uptake}

\section{Cell culture}

The $\mathrm{HepG}_{2}$ cell line was cultured in RPMI-1640 medium with $10 \% \mathrm{FBS}$ and maintained at $37^{\circ} \mathrm{C}$ in an atmosphere containing $5 \% \mathrm{CO}_{2}$. When the cells covered $75 \%-85 \%$ of the flask bottom, the cell medium was removed and the cells were thrice-flushed with PBS. The cells were detached from the flask by digestion with a $0.25 \%$ trypsin solution, and centrifuged at $1000 \mathrm{rpm}$ for $10 \mathrm{~min}$, then transferred to new flasks with fresh RPMI1640 medium supplemented with $10 \%$ FBS.

\section{Cellular uptake}

HepG2 cells $\left(1 \times 10^{5}\right.$ cells/well $)$ were cultured in 24well plates with RPMI-1640 medium to determine cellular uptake. Cells were incubated with GA-S, GA-LP, and Gal-GA-LP containing $90 \mu \mathrm{mol} / \mathrm{L}$ of GA concentration for $6 \mathrm{~h}$. After incubation, the cells were put in $500 \mu \mathrm{L}$ of distilled water at $-80^{\circ} \mathrm{C}$ three times, and then centrifuged at $12,000 \mathrm{r} / \mathrm{min}$ for $10 \mathrm{~min}\left(4^{\circ} \mathrm{C}\right)$. Ethyl acetate $(1.5 \mathrm{~mL})$ was added, vortexed for $5 \mathrm{~min}$, and centrifuged again. The supernatant was evaporated in a vacuum oven at low temperature. The residue was reconstituted with $200 \mu \mathrm{L}$ of methanol, vortex-mixed for $1 \mathrm{~min}$, then centrifuged at 12 $000 \mathrm{r} / \mathrm{min}$ for $10 \mathrm{~min}\left(4^{\circ} \mathrm{C}\right)$. Then, a $10 \mu \mathrm{L}$ aliquot of the sample was injected into a BDS HYPERSIL $\mathrm{C}_{18}$ column (5 $\mu \mathrm{m}, 250 \times 4.6 \mathrm{~mm})$. The composition of the mobile phase consisted of methanol-1 \% acetic acid (89:11 [v/v]). The analysis was performed at a flow of $1 \mathrm{~mL} \cdot \mathrm{min}^{-1}$ by UV detector at $254 \mathrm{~nm}$ and $35^{\circ} \mathrm{C}$. Finally, the concentration of GA was analyzed.

A competitive binding experiment was developed to evaluate the Gal receptor, which specifically mediated the cellular uptake of GA in Gal-GA-LP. HepG2 cells $\left(1 \times 10^{5} \mathrm{cells} /\right.$ well $)$ were seeded and exposed to $90 \mu \mathrm{mol} / \mathrm{L}$ Gal for $4 \mathrm{~h}$, then incubated with GA-S, GA-LP, and GalGA-LP for $6 \mathrm{~h}$. The subsequent process was the same as the above cellular uptake assay.

\section{Pharmacokinetics and bio-distribution studies}

Animal experiments were performed according to the Guidelines of the Animal Center of Guangzhou University of Chinese Medicine. Animals were fed a standard laboratory diet with free access to water at a controlled temperature of $20-22^{\circ} \mathrm{C}$ and relative humidity of $65 \%$ with a $12 \mathrm{~h} \mathrm{light/dark} \mathrm{cycle.} \mathrm{Mice} \mathrm{were} \mathrm{kept} \mathrm{fasting} \mathrm{overnight}$ with free access to water before experiments. One hundred thirty-five healthy Kunming mice $(18 \pm 5 \mathrm{~g})$ were randomly and evenly divided into three groups (GA-S, GA-LP, and Gal-GA-LP). Each group of mice was injected with a dose of $15.6 \mathrm{mg} / \mathrm{kg}$ via the caudal vein. Groups of five mice per liposome formulation per time point were used in this study. After injection, blood samples $(0.50 \mathrm{~mL})$ were obtained and collected directly into heparinized test tubes from the retroorbital plexus at various times $(0.08,0.25,0.5,1,2,4,6$, 12 , and $24 \mathrm{~h}$ ). Mice were euthanized immediately, and the hearts, livers, spleens, lungs, and kidneys were collected. Plasma was separated by centrifugation $(12,000 \mathrm{rpm}$ for 10 min at $4^{\circ} \mathrm{C}$ ), then stored at $-20^{\circ} \mathrm{C}$ until use. Tissue samples were washed with ice cold physiologic saline, blotted, then wiped with filter paper, weighed, and homogenized in a 5 -fold volume of normal saline $(\mathrm{w} / \mathrm{v})$. Homogenates were stored at $-20^{\circ} \mathrm{C}$ until use. The following steps were performed in the preparation of plasma and tissue samples. The parameters were measured by a non-compartmental analysis using a DAS 2.0 computer program. According to the Pharmacopoeia of the People's Republic of China (2010 edition, part II), three distribution parameters (Re, Te, and Ce) for evaluation of liver targeting were measured [43]. 
The relative intake rate $(\mathrm{Re})$ representing the target tissue was calculated as follows:

$$
\mathrm{Re}=\mathrm{AUC}_{\text {liposome }} / \mathrm{AUC}_{\text {solution }} \text { Eq. } 6
$$

Targeting efficiency (Te), which indicates the target efficiency, was calculated as follows:

$$
\mathrm{Te}(\%)=\mathrm{AUC}_{\text {target }} / \mathrm{AUC}_{\text {total }} * 100 \% \quad \text { Eq.7 }
$$

The peak concentration ratio $(\mathrm{Ce})$, which indicates the change in drug distribution, was calculated as follows:

$$
\mathrm{Ce}=\left(\mathrm{C}_{\text {max }}\right)_{\text {liposome }} /\left(\mathrm{C}_{\text {max }}\right)_{\text {solution }} \text {. Eq.8 }
$$

\section{LC-MS/MS analysis of GA}

\section{Chromatographic conditions}

The HPLC system consisted of 4-mode Surveyor LC pumps, a Surveyor autosampler, a CBM-20 system controller, and a Surveyor PDA. A BDS HYPERSIL C18 column ( $5 \mathrm{~mm}, 50 \times 2.1 \mathrm{~mm}$; Thermo) equipped with a $35^{\circ} \mathrm{Ccolumn}$ temperature was used for separation. The mobile phase consisted of acetonitrile and $5 \mathrm{mmoL}$ ammonium acetate solvent $(70: 30[\mathrm{v} / \mathrm{v}])$. The solvent was filtered through a $0.22-\mu \mathrm{m}$ filter and degassed. The ultraviolet (UV) absorption of GA in the samples was measured at 254 $\mathrm{nm}$ by injecting a $5 \mu \mathrm{L}$ volume into the column with a flow rate of $0.3 \mathrm{~mL} / \mathrm{min}$. The total run time was $5 \mathrm{~min}$.

\section{Mass spectrometric conditions}

Mass spectrometer was conducted by a TSQ Quantum MS/MS system (Thermo). Following optimization of the settings, the instrument parameters were set at a nitrogen gas temperature of $300^{\circ} \mathrm{C}$, spray voltage of $3000 \mathrm{~V}$, sheath gas pressure of $30 \mathrm{psi}$, auxiliary gas pressure of $10 \mathrm{psi}$, and capillary temperature of 300 ${ }^{\circ} \mathrm{C}$. The collision gas pressure for MS/MS was maintained at $34 \mathrm{~V}$, and the scanning time was $5 \mathrm{~min}$. Quantification was performed in selective reaction monitoring (SRM) to monitor the transition of $\mathrm{m} / \mathrm{z} 469.26 \rightarrow 387.11$ for $\mathrm{GA}$ and $\mathrm{m} / \mathrm{z} 455.24 \rightarrow 409.09$ for IS, respectively.

\section{Preparation of standard and quality control (QC) samples}

GA $(400 \mu \mathrm{g} / \mathrm{mL})$ and IS $(400 \mu \mathrm{g} / \mathrm{mL})$ were made with methanol. Calibration standard solutions with concentrations of $4,5,10,25,50,100,200,500,1000$, 2000, and $6000 \mathrm{ng} / \mathrm{mL}$ were made with methanol. The GA working solutions for QC samples at 3 different concentrations $(25,800$, and $2000 \mathrm{ng} / \mathrm{mL})$ were prepared in the same manner. The IS working solution (1000 ng/ $\mathrm{mL}$ ) was prepared in methanol from the IS stock solution. All the solutions were kept at $-20^{\circ} \mathrm{C}$ and placed for approximately $5 \mathrm{~min}$ at room temperature before use.

A small amount of tissues was collected, weighed, and homogenized in normal saline (tissue-water ratio of 1:5 [w/v]). The plasma and tissue homogenates were used for the preparation of GA standards and QC samples. The $200 \mu \mathrm{L}$ calibration standard solution at concentrations of $4,5,10,25,50,100,200,500,1000$, 2000, and $6000 \mathrm{ng} / \mathrm{mL}$ was evaporated to dryness in a vacuum oven at low temperature, with addition of 200 $\mu \mathrm{L}$ of blank plasma or homogenates, $50 \mu \mathrm{L}$ of IS working solution, and $1.3 \mathrm{~mL}$ of ethyl acetate, then vortex-mixed, centrifuged, and dried. The residue was added in $200 \mu \mathrm{L}$ of acetonitrile to obtain concentrations of $4,5,10,25$, $50,100,200,500,1000,2000$, and $6000 \mathrm{ng} / \mathrm{mL}$. The QC samples were prepared in the same manner at low, medium, and high GA concentrations (25, 800 and 2000 $\mathrm{ng} / \mathrm{mL}$, respectively).

\section{Plasma and tissue sample preparation}

Plasma and tissue samples were treated by liquidliquid extraction. Tissue samples (tissue: water=1:5 [w/v]) were homogenized with saline to form homogenates. Plasma or tissue homogenates $(200 \mu \mathrm{L}), 50 \mu \mathrm{L}(1 \mu \mathrm{g} / \mathrm{mL})$ UA (IS), and $1.3 \mathrm{~mL}$ ethyl acetate were added to a $2 \mathrm{~mL}$ centrifuge tube. The mixture was vigorously vortex-mixed for $5 \mathrm{~min}$, then centrifuged at $12000 \mathrm{r} / \mathrm{min}$ for $10 \mathrm{~min}$ $\left(4^{\circ} \mathrm{C}\right)$ to obtain a clean supernatant. The clean supernatant was transferred into a 2-mL clean test tube and evaporated to dryness in a vacuum oven at low temperature. The residue was reconstituted with $200 \mu \mathrm{L}$ of acetonitrile, vortex-mixed for $1 \mathrm{~min}$, then centrifuged at $12000 \mathrm{r} / \mathrm{min}$ for $10 \mathrm{~min}\left(4^{\circ} \mathrm{C}\right)$. Then, a $5 \mu \mathrm{L}$ aliquot of the supernatant was injected into the LC-MS/MS system for analysis.

\section{Validation of the analytic method}

The LC-MS/MS method was performed strictly in accordance with the FDA guidelines for validation of the bio-analytical method [44].

\section{Specificity and selectivity}

Specificity was investigated by analyzing samples (plasma or tissue homogenates) of a blank matrix with and without GA and IS. The selectivity of the method was assessed to determine the potential interference of endogenous compounds. The chromatograms of blank plasma or tissue homogenates were compared with blank plasma or tissue homogenates spiked with standard GA or IS, which is a random plasma or tissue homogenate sample after administration of GA and a random sample spiked with IS.

\section{Linearity}

Calibration curves consisting of various concentrations $(4,5,10,25,50,100,200,500,1000$, 2000 , and $6000 \mathrm{ng} / \mathrm{mL}$ ) were performed from working standard solutions of GA by plotting the concentrations of GA in plasma or tissues. The calibration curve was typically described by the equation $\mathrm{Y}=\mathrm{aX}+\mathrm{b}$, where $\mathrm{Y}$ is the peak area ratio of GA:IS, and $\mathrm{X}$ is the concentration of GA. Each concentration sample was measured three times. 


\section{Limit of quantification (LOQ)}

The limit of quantification (LOQ) was defined as the lowest concentration in the calibration curve that could be determined with sufficient precision $<20 \%$ and an accuracy within $\pm 20 \%$. The LOQ was established in 5 continuous days for 6 replicates. The limit of detection (LOD) was defined as a signal-to-noise ratio of 3:1.

\section{Precision and accuracy}

The intra- and inter-day precision (expressed as the relative standard deviation [RSD]) and accuracy (expressed as the relative error $[\mathrm{RE}]$ ) were determined. The intra-day precision and accuracy were evaluated by analyzing six replicates of the plasma and tissue homogenate samples at concentrations of 25,800 , and $2000 \mathrm{ng} / \mathrm{mL}$. The inter-day precision and accuracy was measured by QC samples (plasma and tissue homogenate) over 6 continuous days.

\section{Recovery and matrix effect (ME)}

The extraction recoveries of GA and IS were calculated by comparing the peak area of pre-spiked samples with post-spiked samples by three concentrations for six replicates. The matrix effect was determined by measuring the corresponding peak ratio (analyte: IS) of the post-spiked samples. The same reference solution prepared in the mobile phase was used to measure the analyte peak ratio (anayte: IS) of GA: IS. Experiments were performed at concentration levels of 25, 800, and $2000 \mathrm{ng} / \mathrm{mL}$ for 6 replicates.

\section{Stability}

Sample stability was measured by analyzing the measured concentrations of low, medium, and high QC levels. The QC samples were evaluated under the following 3 storage conditions: (1) short-term stability at room temperature of $25^{\circ} \mathrm{C}$ for $24 \mathrm{~h}$; (2) three frozen-thaw cycles at $-20^{\circ} \mathrm{C}$; and (3) long-term stability at $-20^{\circ} \mathrm{C}$ for 1 month.

\section{Statistical analysis}

The pharmacokinetic parameters, including $\mathrm{T}_{1 / 2 \mathrm{z}}$, $\mathrm{CL}, \mathrm{V}_{\mathrm{d}}$, AUC, MRT, and bio-distribution data, were calculated using a statistical moment algorithm (Drug and Statistics by DAS 2.0 program). Statistical significance of the differences among groups was determined using one-way analysis of variance (ANOVA), and single and multiple comparisons were performed using t-tests for independent groups to assume equal variance within each group. The results are presented as the mean \pm standard deviation (S.D.). A $p<0.05$ was set as the significance level for all tests.

\section{Author contributions}

YC, YHG designed and supervised experiments, JC, YCC designed and executed experiments and wrote the manuscript, CNL, YDT, ZL performed statistical analyses. PJZ, ZC, WHL provided technical support. All authors read and approved the final manuscript.

\section{ACKNOWLEDGMENTS}

We thank Hua Nie and Lihua Luo for their technical help.

\section{CONFLICTS OF INTEREST}

The other authors declare no conflicts of interest.

\section{FUNDING}

This research was supported by the Special Fund of Public Welfare and Ability Building in Guangdong (2014A020210023) and the Ministry of Education Funds Tutor Project (No. 20134425110010).

\section{REFERENCES}

1. Takeda S, Ishihara K, Wakui Y, Amagaya S, Maruno M, Akao T, Kobashi K. Bioavailability study of glycyrrhetic acid after oral administration of glycyrrhizin in rats; relevance to the intestinal bacterial hydrolysis. J Pharm Pharmacol. 1996; 48:902-905. https://doi. org/10.1111/j.2042-7158.1996.tb05998.x.

2. Van Rossum TG, Vulto AG, Hop WC, Brouwer JT, Niesters HG, Schalm SW. Intravenous glycyrrhizin for the treatment of chronic hepatitis $\mathrm{C}$ : a doubleblind, randomized, placebo-controlled phase I/II trial. J Gastroenterol Hepatol. 1999; 14:1093-1099. https://doi. org/10.1046/j.1440-1746.1999.02008.x.

3. Kiso Y, Tohkin M, Hikino H, Hattori M, Sakamoto T, Namba T. Mechanism of antihepatotoxic activity of glycyrrhizin. I: Effect on free radical generation and lipid peroxidation. Planta Med. 1984; 50:298-302. https://doi. org/10.1055/s-2007-969714.

4. Moro T, Shimoyama Y, Kushida M, Hong YY, Nakao S, Higashiyama R, Sugioka Y, Inoue H, Okazaki I, Inagaki Y. Glycyrrhizin and its metabolite inhibit Smad3-mediated type I collagen gene transcription and suppress experimental murine liver fibrosis. Life Sci. 2008; 83:531-539. https:// doi.org/10.1016/j.1fs.2008.07.023.

5. Jeong HG, You HJ, Park SJ, Moon AR, Chung YC, Kang K, Chun HK. Hepatoprotective effects of 18betaglycyrrhetinic acid on carbon tetrachloride-induced liver injury: inhibition of cytochrome P450 2E1 expression. Pharmacol Res. 2002; 46:221-227. https://doi.org/10.1016/ s1043-6618(02)00121-4.

6. Doll R, Hill ID, Hutton C, Underwood DJ. Clinical trial of a triterpenoid liquorice compound in gastric and duodenal ulcer. Lancet. 1962; 2:793-796. 
7. Ohuchi K, Kamada Y, Levine L, Tsurufuji S. Glycyrrhizin inhibits prostaglandin E2 production by activated peritoneal macrophages from rats. Prostaglandins Med. 1981; 7:457463. https://doi.org/10.1016/0161-4630(81)90033-1.

8. Ito M, Sato A, Hirabayashi K, Tanabe F, Shigeta S, Baba M, De Clercq E, Nakashima H, Yamamoto N. Mechanism of inhibitory effect of glycyrrhizin on replication of human immunodeficiency virus (HIV). Antiviral Res. 1988; 10:289-298. https://doi. org/10.1016/0166-3642(88)90047-2.

9. Abe $\mathrm{N}$, Ebina $\mathrm{T}$, Ishida $\mathrm{N}$. Interferon induction by glycyrrhizin and glycyrrhetinic acid in mice. Microbiol Immunol. 1982; 26:535-539. https://doi. org/10.1111/j.1348-0421.1982.tb00207.x.

10. Serra A, Vehlinger DE, Ferrari P, Dick B, Frey BM, Frey FJ, Vogt B. Glycyrrhetinic acid decreases plasma potassium concentrations in patients in patients with anuria. J Am Soc Nephrol. 2002; 13:191-196.

11. Parveen S, Misra R, Sahoo SK. Nanoparticles: a boon to drug delivery, therapeutics, diagnostics and imaging. Nanomedicine. 2012; 8:147-166. https://doi.org/10.1016/j. nano.2011.05.016.

12. Chang HI, Yeh MK. Clinical development of liposomebased drugs: formulation, characterization, and therapeutic efficacy. Int J Nanomedicine. 2012; 7:49-60. https://doi. org/10.2147.IJN.S26766.

13. Torchilin VP. Recent advances with liposomes as pharmaceutical carriers. Nat Rev Drug Discov. 2005; 4:145-160. https://doi.org/10.1038/nrd1632.

14. Allen TM, Cullis PR. Liposomal drug delivery systems: from concept to clinical applications. Adv Drug Deliv Rev. 2013; 65:36-48. https://doi.org/10.1016/j.addr.2012.09.037.

15. Nekkanti V, Kalepu S. Recent advances in liposomal drug delivery: a review. Pharm Nanotechnol. 2015; 3:35-55.

16. Grewal PK. The Ashwell-Morell receptor. Methods Enzymol. 2010; 479:223-241. https://doi.org/10.1016/ S0076-6879(10)79013-3.

17. Poelstra K, Prakash J, Beljaars L. Drug targeting to the diseased liver. J Control Release. 2012; 161:188-197. https://doi.org/10.1016/j.jconrel.2012.02.011.

18. Detampel P, Witzigmann D, Krähenbühl S, Huwyler J. Hepatocyte targeting using pegylatedasialofetuinconjugated liposomes. J Drug Target. 2014; 22:232-241. https://doi.org/10.3109/1061186X.2013.860982.

19. Kawakami S, Hashida M. Glycosylation-mediated targeting of carriers. J Control Release. 2014; 190:542-555. https:// doi.org/10.1016/j.jconrel.2014.06.001.

20. Wang SL, Yu FB, Jiang TY, Sun CS, Wang TY, Zhang JH. Design and synthesis of novel galactosylated polymers for liposomes as gene drug carriers targeting the hepatic asialoglycoprotein receptor. J Drug Target. 2008; 16:233242. https://doi.org/10.1080/10611860801902609.

21. Nie H, Cheng Y, Zheng PJ, Luo LH, Zhang SY. Lipasecatalyzed synthesis of novel galactosylated cholesterol.
Chin Chem Lett. 2015; 26:543-546. https://doi. org/10.1016/j.cclet.2015.01.005.

22. Wang Y, Yuan J, Xiao J, Cai QL, Wang XH, An R, Ma YM. Pharmacokinetics of active ingredients of Radix Glycyrrhizae in rats with oral administration of Banxia Xiexin decoction and its different compatibilities. Chin J Pharm Anal. 2012; 32:1331-1338.

23. Luan X, Guan YY, Liu YR, Wang C, Zhao M, Lu Q, Tang YB, Wang XL, Fang C, Chen HZ. Development and validation of a quantitative liquid chromatography tandem mass spectrometry assay for pristimerin in rat plasma. J Chromatogr B Analyt Technol Biomed Life Sci. 2013; 941:25-30. https://doi.org/10.1016/j.jchromb.2013.09.038.

24. Jia HJ, Jia FY, Zhu BJ, Zhang WP. Preparation and characterization of Glycyrrhetinic-acid loaded PEGmodified liposome based on PEG-7 glyceryl cocoate. Eur J Lipid Sci Technol. 2017. https://doi.org/10.1002/ ej1t.2016.00010.

25. Cai YE, Xu YQ, Chan HF, Fang XB, He CW, Chen MW. Glycyrrhetinic acid mediated drug delivery carriers for hepatocellular carcinoma therapy. Mol Pharm. 2016; 13:699-709. https://doi.org/10.1021/acs. molpharmaceut.5b.00677.

26. Guo BH, Cheng Y, Wu W, Lin LP, Lin DH. HPLC assay and pharmacokinetics and tissue distribution study of glycyrrhetinic acid liposomes modified with galactosylated lipid. J Liposome Res. 2012; 22:120-127. https://doi.org/1 0.3109/08982104.2011.627515.

27. Lu Y, Li J, Wang GJ. In vitro and in vivo evaluation of mPEG-PLA modified liposomes loaded glycyrrhetinic acid. Int J Pharm. 2008; 356:274-281. https://doi.org/10.1016/j. ijpharm.2007.12.047.

28. Guo BH, Cheng Y, Li NY, Li X, Jin M, Li T, Li J. In vitro and in vivo studies of galactose-modified liver-targeting liposomes. J Drug Target. 2013; 21:257-264. https://doi. org/10.3109/1061186X.2012.741135.

29. Maruyama, K. Intracellular targeting delivery of liposomal drugs to solid tumors based on EPR effects. Adv Drug Deliv Rev. 2011; 63:161-169. https://doi.org/10.1016/j. addr.2010.09.003.

30. Dong Y, Feng SS. Methoxy poly (ethylene glycol)poly(lactide) (MPEG-PLA) nanoparticles for controlled delivery of anticancer drug. Biomaterials. 2004; 25:28432849. https://doi.org/10.1016/j.biomaterials.2003.09.055.

31. Guhagarkar SA, Majee SB, Samad A, Devarajan PV. Evaluation of pullulan-functionalized doxorubicin nanoparticles for asialoglycoprotein receptor-mediated uptake in HepG2 cell line. Cancer Nanotechnol. 2011; 2:49-55. https://doi.org/10.1007/s12645-011-0012-x.

32. Liang HF, Yang TF, Huang CT, Chen MC, Sung HW. Preparation of nanoparticles composed of poly(gammaglutamic acid)-poly(lactide) block copolymers and evaluation of their uptake by HepG2 cell. J Control 
Release. 2005; 105:213-225. https://doi.org/10.1016/j. jconrel.2005.03.021.

33. Zhu XL, Du YZ, Yu RS, Liu P, Shi D, Chen Y, Wang Y, Huang FF. Galactosylated chitosan oligosaccharide nanoparticles for hepatocellular carcinoma cell-targeted delivery of adenosine triphosphate. Int J Mol Sci. 2013; 14:15755-15766. https://doi.org/10.3390/ijms.140815755.

34. Li J, Yu H, Li S, Wang GJ. Enhanced distribution and extended elimination of glycyrrhetinic acid mice liver by mPEG-PLA modified (mPEGylated) liposome. J Pharm Biomed Anal. 2010; 51:1147-1153. https://doi. org/10.1016/j.jpba.2009.11.005.

35. Wu W, Cheng Y, Guo BH, Wu Q. Pharmacokinetics of livertargeted docetaxel liposomes modified with 6-O-acyl-Dgalactose esters in rabbits. Biomed Rep. 2014; 2:545-548. https://doi.org/10.3892/br.2014.285.

36. Wang SN, Deng YH, Xu H, Wu HB, Qiu YK, Chen DW. Synthesis of a novel galactosylated lipid and its application to the hepatocyte-selective targeting of liposomal doxorubicin. Eur J Pharm Biopharm. 2006; 62:32-38. https://doi.org/10.1016/j.ejpb.2005.07.004.

37. Biessen EA, Beuting DM, Roelen HC, Van de Marel GA, Van Boom JH, Van Berkel TJ. Synthesis of cluster galactosides with high affinity for the hepatic asialoglycoprotein receptor. J Med Chem. 1995; 38:15381546. https://doi.org/10.1021/jm00009a014.

38. Anonymous. The guide for the care and use of laboratory animals. ILAR J. 2016; 57:NP. https://doi.org/10.1093/ilar/ ilw049.
39. Zu YG, Zhang Y, Zhao XH, Zhang Q, Liu Y, Jiang R. Optimization of the preparation process of vinblastine sulfate (VBLS)-loaded folate conjugated bovine serum albumin (BSA) nanoparticles for tumor-targeted drug delivery using response surface methodology (RSM). Int J Nanomedicine. 2009; 4:321-333.

40. Food and Drug Administration, HHS. International conference on harmonisation; stability data package for registration applications in climatic zones III and IV; stability testing of new drug substances and products; availability. Fed Regist. 2003; 68:65717-65718.

41. Zu YG, Meng L, Zhao XH, Ge YL, Yu XY, Zhang Y, Deng YP. Preparation of 10-hydroxycamptothecin-loaded glycyrrhizic acid-conjugated bovine serum albumin nanoparticles for hepatocellular carcinoma-targeted drug delivery. Int J Nanomedicine. 2013; 8:1207-1222. https:// doi.org/10.2147/IJN.S40493.

42. Lian H, Sun J, Yu YP, Liu YH, Cao W, Wang YJ, Sun YH, Wang SL, He ZG. Supramolecular micellar nanoaggregates based on a novel chitosan/vitamin E succinate copolymer for paclitaxel selective delivery. Int J Nanomedicine. 2011; 6:3323-3334. https://doi.org/10.2147/IJN.S26305.

43. Chinese Pharmacopoeia Commission. (2010). Pharmacopoeia of the People's Republic of China. Part II, 2010 edition. The Medicine Science and Technology Press of China.

44. Zimmer D. New US FDA draft guidance on bioanalytical method validation versus current FDA and EMA guidelines: chromatographic methods and ISR. Bioanalysis. 2014; 6:13-19. https://doi.org/10.4155/BIO.13.298. 